\title{
The Intestinal Microbiome and Surgical Disease
}

\author{
Monika A. Krezalek, MD*, Kinga Skowron, MD*, Kristina L. Guyton, MD*, Baddr Shakhsheer, \\ MD*, Sanjiv Hyoju, MD, and John C. Alverdy, MD FACS \\ Center for Surgical Infection Research and Therapeutics Pritzker School of Medicine, University \\ of Chicago, Department of Surgery, 5841 S. Maryland, Chicago, Illinois 60637
}

\section{Introduction}

The human body is covered with 100 trillion bacterial cells. The normal human microbiome has a complex symbiotic relationship with the human body and immune system. Unique communities of bacteria populate our skin, lungs, genital tract and intestinal tract: each with distinct sub-communities defined by the adjoining cells, the availability of nutrients and immune interactions. ${ }^{1}$ Although it is recognized that humans are multicellular organisms, that this multicellularity includes its microbiome and its various interactions with other ecosystems is less well recognized. Scientists are just now beginning to understand the intricate interactions between the human body and the bacteria that live on and within it.

\section{The Human Microbiome Project}

The past 30 years have seen an explosion of information about the genetic material that makes up human life. Initially, this investigation was focused on human genetic composition and variation, lead chiefly by the Human Genome Project. Between 1990 and 2003, this international collaborative of scientists successfully sequenced over 20,000 genes, creating a map of the human genome. In the process, they continually improved methods of processing and storing high volumes of genetic information and tackled the legal and ethical issues intertwined with use of genetic data. This project has served as the basis for many subsequent collaborative projects that investigate genetic variation and protein transcription. $^{2}$

Human genetic composition is only one component of a complicated algorithm that determines health and disease. Scientists are just beginning to appreciate the complex interaction between the human host and its microbiome. In the early $20^{\text {th }}$ century, with a new understanding of germ theory and the development of antibiotics, society and modern medicine began an assault on the bacterial world both inside and outside of the body. However, over the past two decades, amid increasing bacterial resistance and autoimmune

Correspondence: John C. Alverdy MD FACS, Professor of Surgery, University of Chicago, 5841 S Maryland MC6090, Chicago, Il 60637, jalverdy@surgery.bsd.uchicago.edu, 773-702-4876 FAX: 773-834-0201.

Equal contribution authors

Publisher's Disclaimer: This is a PDF file of an unedited manuscript that has been accepted for publication. As a service to our customers we are providing this early version of the manuscript. The manuscript will undergo copyediting, typesetting, and review of the resulting proof before it is published in its final citable form. Please note that during the production process errors may be discovered which could affect the content, and all legal disclaimers that apply to the journal pertain. 
disorders, we have learned that the human microbiome is vital to our health and that its disruption and imbalance can lead to disease.

Beginning with Pasteur, the study of microbiology has depended on the ability to grow and propagate microorganisms through culturing techniques. Identification, characterization and genetic sequencing were initially only possible for purified cultures. Even with elaborate culturing techniques, only a small fraction of the bacterial world was identified. As genetic evaluation methods advanced, smaller and smaller amounts of DNA were needed for identification. By 2005, researchers were analyzing the intestinal microbiota using molecular fingerprinting and sequence analysis of cloned microbial small-subunit ribosomal RNA genes (16S ribosomal DNA (rDNA)). Their analysis demonstrated that the majority of species present in the intestine were novel microorganisms not previously identified by available culturing techniques and distinct patterns of bacterial colonization in different body habitats. $^{3}$

With the recognition of this significant knowledge deficit, the United States National Institute of Health launched the Human Microbiome Project, an initiative to identify and characterize microorganisms that are found in association with human health and disease. ${ }^{4}$ Started in 2008 as a 5-year feasibility study, the Human Microbiome Project addressed five primary goals: (1) To develop a reference set of microbial genome sequences and to perform preliminary characterization of the human microbiome, (2) To explore the relationship between disease and changes in the human microbiome, (3) To develop new technologies and tools for computational analysis, (4) To establish a resource repository, and (5) To study the ethical, legal, and social implications of human microbiome research. Five body sites were emphasized: oral, skin, vagina, gut and nasal/lung. As the project advanced, further refined culture-independent methods of analysis were developed, including metagenomics, deep sequencing of 16S rRNA, and whole genome sequencing. Thus far, over 536 peerreviewed publications have been associated with this project. ${ }^{4}$ The ongoing investigation has already led to an enormous advance in the understanding of microbiome development, stability and alterations associated with health and disease. The human microbiome is a dynamic ecosystem that is acutely responsive to the environment and to the human body. 5,6 This review will summarize some of the important discoveries that relate our bacterial counterparts to human health and disease.

\section{Microbiome Development}

The development of the human microbiome begins very early in life and is highly dependent on the surrounding environment. The bacterial composition of an infant's meconium is similar to the bacteria found in the maternal placenta. ${ }^{7}$ In fact, unlike adults, neonates have undifferentiated microbiome communities throughout the body, perhaps reflective of the fact that prior to delivery they were uniformly bathed in amniotic fluid. ${ }^{8}$ Within 10 days of delivery, the infant microbiome undergoes critical changes; the bacterial communities of the different body habitats become distinct. Interestingly, these bacterial ecosystems are reflective of the mode of delivery: the first exposure to the world outside the womb. Compared to infants delivered vaginally, those born by cesarean section have a different intestinal microbiome with lower populations of Bacteroides. ${ }^{910}$ This population of 
Bacteroides is thought to contribute to complex carbohydrate digestion and important interactions with the developing immune system. ${ }^{11}$ Further research is necessary to understand the consequences of this bifurcation in newborn microbiome populations.

It is increasingly evident that the human body and the microbiome are mutually dependent and adapted to function together. The microbiome performs functions integral to human survival. Colonic bacteria break down ingested carbohydrates, proteins and fatty acids into nutrients that can be absorbed by our intestine. ${ }^{12-15}$ Commensal bacteria stimulate increased epithelial mucosal barrier function. The immune system develops and learns from exposure to the bacteria present in our intestines. ${ }^{16}$ If this bacterial-immune interchange does not take place, as demonstrated in germ-free mice, T helper cell development is impaired. ${ }^{17} \mathrm{In}$ another experimental model, piglets kept indoors with strict hygiene protocols were subsequently shown to have low intestinal microbial diversity and impaired immune responses. ${ }^{18,19}$ Microbiome development begins in the womb and continues to evolve throughout life. The health implications of a low diversity microbiome and inadequate immune stimulation may include metabolic, allergic, infectious, inflammatory and autoimmune diseases. ${ }^{20}$

While the initial development of the human microbiome is greatly affected by early bacterial exposure, the established adult microbiome is relatively stable. ${ }^{21}$ On a small scale the intestinal microbiome fluctuates on a daily and even hourly basis, depending on the individual's diet, daily habits and interactions with other animals and people. ${ }^{5,22}$ Lifestyle choices — diet, exercise, smoking, environment and pets—significantly affect the microbiome. ${ }^{22-26}$ Notable changes in the microbiome are detected within one day of an alteration in diet. ${ }^{22}$ However, despite constant fluctuations, the microbiome tends to return to a baseline. ${ }^{21}$ Interestingly, each individual's unique pattern of microbial colonization is shed onto our environment, altering the bacterial profile of any surface touched by an individual. This technology is beginning to be applied in forensics as the individual microbial signature is so distinct that it can be used to identify who has been present in a given location. ${ }^{27}$ This technology may someday inform the pathogenesis of surgical infections as microbial vector transmission can be tracked in space and time.

\section{Microbiome Disruption and Disease}

While the interaction of the microbiome with the human body is important for development and health, there is great variation in what constitutes a normal microbiome among individuals. ${ }^{28}$ This variation has been proposed to contribute to four physiologic processes: modulation of energy homeostasis, modulation of gut barrier integrity, regulation of gastrointestinal peptide hormone secretion, and modulation of the host inflammatory state. ${ }^{29}$ The intestinal mucosa is a site of constant interaction between the luminal bacteria and the host. This delicate balance can be disrupted acutely as seen with antibiotic therapy or acute illness or gradually due to selective environmental pressures. Prolonged alterations in microbiome composition may alter the interaction with mucosal tissues and the immune system. This microbiome imbalance, often termed dysbiosis, can lead to inflammation or susceptibility to infection. ${ }^{30}$ Dysbiosis is thought to contribute to numerous diseases, 
including obesity, inflammatory bowel disease (IBD), cancer and postsurgical complications. ${ }^{31,32}$

Significant disturbances of microbiome structure and function can result from acute physiologic insults, particularly the use of antibiotics. Broad spectrum antibiotics have a rapid and profound impact on microbial diversity. ${ }^{33,34}$ Microbiome recovery after antibiotic therapy occurs over the course of many months and is often incomplete. ${ }^{21,35,36} \mathrm{~A}$ seven day course of clindamycin dramatically perturbs the human intestinal microbiome composition, with a higher incidence of antibiotic-resistant clones in the Bacteroides genus and incomplete recovery even after two years. ${ }^{37,38}$ Similar laboratory studies with multiple different antibiotics have shown prolonged disturbance of the mouse microbiome that persists long after treatment. ${ }^{33}$ Repeated use of antibiotics increases the likelihood of incomplete recovery of the microbiome and development of antibiotic resistence. ${ }^{34,36,39}$ These antibiotic insults depopulate subsets of the microbiota, allowing other bacterial species to "bloom" and develop resistance. In general, a decrease in bacterial diversity due to antibiotic use may predispose the host to intestinal colonization by pathogenic bacteria. ${ }^{40,41}$

Even without the use of antibiotics, acute illness or stress of injury significantly disrupts the intestinal microbiome. A pattern of ecologic collapse is seen following burn, trauma, surgery, acute cardiac events and stroke. ${ }^{42,43}$ When the context of the normal microbeimmune interaction changes, local overgrowth and virulence factor expression among enteric bacteria associated with altered intestinal selectivity can result in sepsis. ${ }^{44,45}$ Interestingly, the most frequent organisms that cause sepsis are among the 10,000 bacterial species that the body encounters on a daily basis. ${ }^{28,46}$ Immunocompromised patients are particularly vulnerable to life threatening bloodstream infections of commensal intestinal bacterial species: Enterococcus, Enterobacteraciae, and Streptococcus. ${ }^{47}$ Preceding bloodstream infection, the stool of patients undergoing allogenic hematopoietic stem cell transplantation (allo-HSCT) demonstrates intestinal domination by the offending bacterial species (accounting for at least 30\% percent of the stool microbial composition). ${ }^{48,49}$ This suggests that overpopulation by a pathogenic enteric bacterial species in a vulnerable host may result in infectious complications and sepsis. Similar observations have also been made in the development of neonatal sepsis. ${ }^{50-53}$ Among such patients, certain bacterial species can evolve highly virulent and resistant phenotypes that arise from the commensal microbiota when the endogenous microbiome and immune balance is disrupted, resulting in bacterial overgrowth and sepsis.

In addition to the risk of systemic infection, dysbiosis causes mucosal inflammation. Persistent bacterial-immune imbalance results in immune activation at mucosal sites and chronic inflammation. ${ }^{30}$ The pathogenesis of inflammatory bowel disease (IBD), Crohn's disease and ulcerative colitis, is now thought to be a combination of genetic predisposition and environmental factors altering the intestinal microbiome. Increased IBD risk is associated with early childhood exposure to environmental triggers found within developed societies, including smoking, urban environment, oral contraceptive use and diet. ${ }^{54,55}$ Current IBD therapy modulates the immune response; evolving therapies aim to modify the intestinal microbiota with antibiotics, probiotics and even fecal microbiota transplant 
(FMT) ${ }^{56}$ Further understanding of how the microbiome contributes to chronic inflammation will allow for development of targeted therapy.

Inflammation is implicated as the initiating and driving factor in many gastrointestinal cancers. Local inflammation induces a shift in the mucosal tissue, driving to the progression to dysplasia and eventually to metaplasia and metastatic ability. ${ }^{57,58}$ In fact, the duration and degree of inflammation in IBD patients correlates with increasing risk of cancer development. ${ }^{59}$ While dysbiosis of the microbiome may lead to progression toward cancer, other members of the intestinal microbiota appear to be beneficial in cancer therapy and actually have been shown to enhance the success of the response to biologic agents. ${ }^{60}$

Despite advances in chemotherapy and radiation, surgery remains the gold standard therapy for gastrointestinal cancers. Yet the process of cancer surgery of the gastrointestinal tract has a significant impact on the intestinal microbiome. A small surgical resection of the colon even without antibiotic use, demonstrated in piglets, causes a sustained alteration in colonic microbial composition for at least two weeks following surgery. ${ }^{43}$ Additionally, many perioperative interventions (antibiotics and bowel preparation) dramatically alter the microbiome. ${ }^{61}$ This microbiome disruption may create selective pressures that encourage the formation of virulent and resistant organisms. ${ }^{62}$ The presence of virulent, collagendegrading bacteria may contribute to postsurgical complications such as anastomotic leak. ${ }^{63}$

The normal microbiome is responsible for nutrient breakdown and processing along the course of the intestinal tract. The microbiome of obese persons shows a higher proportion of Bacteroides, a genus of anaerobic bacteria considered to be responsible for much of the nutrient recovery from the intestinal lumen. ${ }^{64}$ As we will learn in the later sections of this monograph, this may mean that the microbiome of obese people is more effective at extracting energy from food and stimulating lipogenesis. ${ }^{65}$ Importantly, this microbiomerelated obese phenotype is transmissible: the transplant of an obese mouse fecal microbiome to a normal weight germ-free mouse results in dramatic weight gain. ${ }^{66}$ Additionally, when the microbiome of obese mice after Roux-en-Y gastric bypass surgery is transferred into germ-free mice, these mice lose weight and fat mass compared to germ-free mice that received microbiota from mice subjected to sham surgery. Clearly, the microbiome has a significant impact on weight gain and loss, and we are gradually moving toward an understanding of the factors that are responsible for this shift and how they can be manipulated to improve health.

From this brief introduction we can already see that many diseases are attributable to or impacted by the intestinal microbiome. Imbalance of the microbiota involved in nutrient processing may lead to disrupted metabolism and obesity. Bacterial signals can trigger mucosal inflammation, leading to chronic inflammation and tumorigenesis. Surgical intervention results in independent microbiome shifts and rise of aggressive bacteria contributing to postsurgical complications. In the following sections of this monograph we will discuss the fragile balance of the symbiotic host-microbial relationship that is necessary to maintain health and how imbalances in the microbiome can lead to complications from surgery and disease. 


\section{Microbiome and Sepsis}

Post-surgical sepsis remains an important source of postoperative morbidity, long-term complications and mortality. Despite the advances in critical care and antibiotic development, recent decades have seen a rise in post-surgical sepsis and effective therapies for this complex disease process remain scarce. ${ }^{67,68}$ This therapeutic deficit is in part due to our incomplete understanding of the process by which bacteria overwhelm the host immune system, leading to sepsis and associated organ failure. Rigorous scientific discoveries have recently shed light on the powerful contribution of the intestinal microbiome to health and disease, including post-surgical sepsis. It is now believed that the stress of surgery coupled with physiologic changes associated with critical illness alter the delicate homeostasis of the intestinal milieu, leading to dysregulated crosstalk between the intestinal epithelium, immune system and the numerous microbiota contained within the gut. ${ }^{69,70}$ With recent innovations in methods to elucidate the composition and function of the gut microbiome, a more complete understanding of the diverse ecosystem of the human intestinal microbiome and its role in sepsis is now possible. $3,71,72$

\section{Human Intestine and its Microbiome as the "Driver" of Critical IIIness and Sepsis}

Devoid of physiologic stressors, the healthy intestinal environment is abundant in nutrients, supplying unlimited fuel to both the host cells and their microbial counterparts, maintaining a delicate symbiotic liaison. However, the physiologic perturbations caused by surgical stress along with selective pressures imposed by antibiotics, hypoxia and nutrient depletion cause this delicate balance to be altered. The resident microbes can no longer be supported by these harsh intestinal conditions and must adapt to survive. These selective pressures lead to alterations in the composition and function of the intestinal microbiome with profound effects on the host immune system and the course and outcome of post-surgical recovery. ${ }^{73}$

Starting in the 1980s, scientists began to suspect that the human intestine was the "driver" of critical illness and sepsis. ${ }^{74}$ Many theories arose to explain how the intestinal microbes gain access to and cause inflammation within their host, leading to sepsis. Initially, the theory of "gut-derived" sepsis centered on the hypothesis of the "leaky gut." It was believed that the stressors imposed on the human body lead to the breakdown of the intestinal barrier. This increased intestinal permeability and translocation of bacteria into the previously sterile blood compartment was postulated to allow microbes to activate the immune system, leading to damage of key organs such as the lung, liver and kidney. ${ }^{75-77}$ In support of this theory, critical illness has been shown to induce alterations to the intestinal mucous layer and damage to the intestinal epithelium, thereby increasing permeability and leading to loss of barrier function. ${ }^{78}$ Furthermore, the presence of bacteria in the blood has been shown to correlate with the severity of critical illness and sepsis. ${ }^{79}$ However, clear evidence in support of the "leaky gut" hypothesis as a sole explanation of the pathophysiology of sepsis is lacking. For one, bacteria and fungi are seldom cultured from the blood stream of critically ill and septic patients, speaking against the idea that the mere presence of bacteremia is responsible for the derangements seen in this complex disease process. ${ }^{79,80}$ In addition, even 
healthy individuals are subject to transient and asymptomatic bacteremia, without development of septic complications. ${ }^{81}$ Therefore, it is now thought that bacterial translocation may be a part of normal human physiology, possibly to allow the immune system exposure to and sampling of the intestinal contents. While bacteremia as a result of "leaky gut" undeniably occurs with sepsis, its clinical relevance is uncertain and bacteremia alone cannot be the sole explanation for the derangements seen in "gut-derived" sepsis.

With lack of evidence to support bacteremia as the inciting cause of gut-derived sepsis, attention was turned to the lymphatics. ${ }^{82}$ The theory "gut-lymph" theory of sepsis postulates that, during physiologic stress, live bacteria and their released factors are able to translocate into the submucosal intestinal lymphatics and mesenteric lymph nodes where they interact with the immune system causing local and systemic immune activation, sepsis and organ failure. ${ }^{83}$ In a series of 927 abdominal laparotomies, MacFie et al. found that $14 \%$ of patients had intestinal bacteria within the mesenteric lymph nodes, a finding that correlated with increased rate of post-operative sepsis. ${ }^{84}$ However, evidence suggests that sepsis and organ failure occur even in the absence of detectable bacteria in the mesenteric lymph nodes. ${ }^{85}$ For example, Lemaire et al. showed that thoracic duct lymph in patients with multiorgan failure seldom contained live bacteria, but did contain small amounts of endotoxin and pro-inflammatory cytokines. ${ }^{86}$ Magnotti et al. discovered that mesenteric lymph collected from animals subjected to trauma and hemorrhagic shock induced increased gut permeability and immune activation, while plasma from the same animals did not. ${ }^{87,88} \mathrm{In}$ addition, the authors discovered that lung injury induced by the same animal model can be ameliorated through the division of the gut lymphatic drainage. ${ }^{88}$ Mesenteric duct ligation has also been shown to significantly improve survival and cardiac function in other animal models of shock. ${ }^{89,90}$ These discoveries lead to the "three hit theory" of gut-origin sepsis proposed by Deitch in 2002. ${ }^{91}$ He hypothesized that injury-induced splanchnic hypoperfusion followed by restoration of intestinal blood flow with resuscitation (ischemiareperfusion) lead to the damage of epithelial barrier function and the translocation of gutderived pro-inflammatory mediators into the lymphatic system, contributing to systemic inflammation and distant organ injury. ${ }^{92}$

While all of these mechanisms have been shown to play partial roles in the pathophysiology of sepsis, it is naïve to think that the gut serves simply as a mechanical barrier to the intestinal microbes. The above mechanisms fail to consider the effects of the altered gut microbiome on the course and outcome of sepsis. The critical role of the intestinal microbiome in sepsis and critical illness is illustrated by studies that employ germ-free animals. In both, hemorrhagic shock and ischemia-reperfusion models, germ-free animals demonstrate improved survival when compared to conventional animals. ${ }^{93,94}$ Therefore, a more complete view that incorporates the role of changing intestinal microbiome and its interactions with the host during health and disease was initially coined by Clark and Coopersmith in 2007 and termed the "intestinal crosstalk" paradigm. ${ }^{69}$ The paradigm considers a three-way symbiotic relationship between the intestinal epithelium, immune system and the commensal bacteria. In the following paragraphs, we will demonstrate how this delicate homeostatic relationship can be disrupted by surgical injury and critical illness and how perturbation to this balance can lead to sepsis and multi-organ failure. 


\section{Perturbations of the Intestinal Milieu during Injury}

While the intestinal mucous layer, epithelium and mucosa-associated immune system provide an important defense against invasive microbes, it is the intact health-promoting intestinal microbiome that is now considered the most important protective element against pathogen invasion. ${ }^{95}$ Commensal bacteria play a critical role in host metabolism, immune homeostasis and provide colonization resistance against accidentally acquired pathogens, meaning those microbes that have not co-evolved with their host. ${ }^{73,96}$ In addition the microbiota provide tonic stimulation of the host immune system via TLR (Toll-like receptor) signaling which strengthens epithelial integrity, optimizes gut motility and leads to the production of factors that maintain a balanced distribution of bacterial symbionts that then protect against invading transient pathogens. ${ }^{97,98}$ Commensals also regulate intestinal inflammation by altering pro-inflammatory signaling pathways in the intestinal epithelium..$^{99,100}$ Bacteria, in turn, have their own system of cell-to-cell signaling termed quorum sensing. Quorum sensing (QS) molecules released by the bacteria provide a system through which bacteria communicate with each other, with the host and with the surrounding microenvironment. ${ }^{101(\mathrm{p}-)}$ Host interception of QS molecules is another example by which the host monitors and responds to changes in the commensal microbiota. ${ }^{102}$ Byproducts of commensal bacterial metabolism in the gut also contribute to homeostasis. For example, a short chain fatty acid butyrate, the primary energy source for colonocytes, is known to dampen the intestinal and systemic immune responses. ${ }^{103,104}$ Butyrate contributes to increased expression of certain heat shock proteins important for epithelial cell viability, barrier integrity, and down regulation of pro-inflammatory cytokines. ${ }^{105}$ Importantly, butyrate-producing bacteria are often lost during critical illness. ${ }^{106}$ The fine-tuned homeostatic balance within the host-microbiome interaction can be readily disrupted by host injury, leading to changes in the composition and function of the intestinal bacteria and further predisposing to immune activation and the development of systemic complications.

Physiologic and tissue related stress associated with host injury, including elective surgery, has been demonstrated to alter the composition and function of the intestinal microbiome. Our laboratory has shown that intestinal resection with anastomosis, a commonly performed colorectal surgical intervention, results in alteration of the abundance of mucosa-associated Enterococcus with an associated increase in virulence activation and collagenase production that predisposes to anastomotic leak and sepsis. ${ }^{63,107}$ In a study of human microbiome composition following burn injury, Earley et al. showed a decrease in the overall diversity of the gut microbiome characterized by an increase in the relative abundance of the family Enterobacteriaceae, represented by many opportunistic pathogens. ${ }^{44}$ In the same study, the authors demonstrated that mice subjected to burn injury experienced alterations of their microbiome as early as the first day post-injury, with overgrowth of Gram-negative aerobic bacteria coupled with increased intestinal permeability. Similarly, Hayakawa et al. showed that in otherwise healthy individuals who suffer a major insult, such as trauma or cardiac arrest, the fecal bacterial composition changed within 6 hours of the incident. ${ }^{108}$

While injury alone has the ability to alter the intestinal microbiome, adjunctive treatments employed in the hospital setting such as use of broad spectrum antibiotics and opioids, restriction of oral intake, and the use of vasoactive mediations have dramatic effects on the 
state of the intestinal microbiome and loss of colonization resistance. For example, intestinal hypo-perfusion and reperfusion injury lead to an altered oxygen gradient in the mucosa and increase nitrate concentration favoring the growth of opportunistic pathogens. ${ }^{109-111}$ Our laboratory has recently shown that critically ill septic patients confined to the intensive care unit, who are exposed to prolonged broad-spectrum antibiotic treatment and life support, suffer a near complete ecologic collapse of their intestinal microbiome, retaining only two to four multidrug resistant healthcare-associated pathogens. ${ }^{70}$ The remarkable depletion of microbiome diversity has been shown to be predictive of sepsis-related mortality. ${ }_{106}$

\section{Rise of the Pathobiome through Bacterial Quorum Sensing and Virulence Activation}

The loss of a protective microbiome seen with injury and critical illness with resultant loss of colonization resistance allows healthcare-acquired opportunistic pathogens to colonize the host, subvert its immune system and succeed in causing infection. These pathogens have unique life histories shaped by repeated exposures to antibiotics and nutrient-poor, hostile environments of other hospitalized patients. ${ }^{70,112}$ They can become further virulized by host compensatory signals produced in response to inflammation and hypoxia, such as inflammatory cytokines, catecholamines, and endogenous opiods. ${ }^{113-117}$ We have demonstrated that an endogenous opioid dynorphin released from the intestinal mucosa following ischemia/reperfusion injury can be intercepted by Pseudomonas aeruginosa quorum sensing circuitry involving signals such as the global transcriptional regulator MvfR and the quorum sensing-related quinolone signaling molecules PQS, HHQ, and HQNO resulting in enhanced virulence. ${ }^{116}$ Furthermore, exposure of Pseudomonas aeruginosa to morphine leads to a dramatic shift to a mucus suppressing, barrier disrupting, and lethal phenotype in a mouse model of gut-derived sepsis. ${ }^{118} \mathrm{We}$ also discovered that intestinal phosphate limitation has a similar ability to induce a lethal phenotype switch of Pseudomonas aeruginosa through the activation of phosphosensory pathways directly related to virulence pathways. ${ }^{119}$ Virulence activation by these pathogens not only results in harm against the host, but also leads to elimination or suppression of the remaining commensals. ${ }^{116}$ One example of this type of opportunism is observed with Salmonella enterica. Normally, the intestinal epithelium produces several antimicrobial peptides such as lipocalin-2 and calprotectin, which sequester iron and zinc from the gut, preventing bacterial overgrowth. Salmonella enterica subverts this protective mechanism by producing salmochelin and the ZnuABC transporter that allow it to obtain these critical nutrients from the intestinal environment and gain a competitive advantage over the commensals. ${ }^{120}$

Along similar lines, evidence shows that certain members of the commensal flora exposed to a hostile intestinal environment are able to increase in abundance and transform via quorum sensing and virulence activation to a more aggressive phenotype. For example, commensal Escherichia coli recovered from a mouse after a partial hepatectomy and short-term starvation display an adherent and barrier-altering phenotype characterized by expression of type 1 fimbriae. ${ }^{121}$ Exposure to broad spectrum antibiotics and epithelial injury transforms commensal E. coli into a multi-drug resistant lethal phenotype capable of inducing severe gut-derived sepsis through Naip5-Nlrc4 infammasome activation. ${ }^{122}$ Similarly, commensal 
Candida albicans is able to switch its phenotype to a lethal hyphae-producing phenotype when exposed to conditions of limited phosphate abundance. Oral supplementation of phosphate reverses this virulence and prevents mortality in a mouse model of lethal gutderived sepsis due to gut $C$. albicans. ${ }^{123}$ As a third example, Clostridium difficile co-exists with its host in low numbers as part of the commensal flora. ${ }^{124}$ However, loss of colonization resistance from antibiotic exposure results in a bloom of this opportunistic pathogen, resulting in toxin production and disease states that vary from diarrhea to toxic megacolon and sepsis. ${ }^{125}$ The newly formed destructive and resistant pathogens (the pathobiome) can engage the intestinal epithelium and immune system leading to the overwhelming inflammatory activation and peripheral organ damage characteristic of sepsis.

\section{Bacteriotherapy in Critical IIIness and Sepsis: Preservation of the Microbiome as a Preventive Strategy}

If the deranged gut pathobiome is the driver and perpetuator of critical illness and sepsis, it is rational to suspect that restoration of the intestinal microbiome can alter the course of critical illness and sepsis, returning host homeostasis. Various strategies to preserve the microbiome composition and function and prevent progression of sepsis, such as the use of probiotics and prebiotics have been proposed. Despite the success in reducing mortality from sepsis in animal studies ${ }^{126}$, probiotics have not been successful in achieving that goal in clinical trials. This is likely due to our limited understanding of the complex interactions that occur in the gut of the critically ill. The use of probiotics, such as Lactobacillus or Bifidobacterium species, have been studied extensively in the critically ill, with some reports of decreased infectious complications. ${ }^{127-129}$ However, none have been able to show survival benefit. In fact, a large multicenter randomized controlled trial (PROPATRIA) published by Besselink et al. revealed that the use of a novel probiotic mixture in critically ill patients with severe acute pancreatitis led to increased mortality compared to placebo. ${ }^{130}$ Importantly, comparisons between these studies are difficult to make as they are confounded by discrepancies between the type and dosages of probiotics studied. There are also concerns regarding the possible risks associated with probiotic use, such as adverse reactions, virulence activation, and transfer of antibiotic-resistance genes. ${ }^{131}$ Additionally, it is difficult to imagine that addition of a few probiotics could restore the complex composition of the health-promoting intestinal microbiome.

Therapeutic strategies that thwart virulence expression and suppress growth of pathogens have shown promise. First such treatment is fecal bacteriotherapy with fecal microbiota transplantation (FMT), where stool of a healthy person is introduced into the gut of a critically ill patient via an oral or rectal route. FMT has shown great success in the treatment of recurrent Clostridium difficile diarrhea. Through expression of toxins within the intestine, C. difficile causes severe diarrhea, intestinal inflammation, and may progress to severe systemic illness and sepsis. ${ }^{132}$ The initial treatments for $C$. difficile diarrhea include the use of antibiotics such as metronidazole or vancomycin, with a $87 \%$ and $97 \%$ success rate, respectively. However, the recurrence rate is very high, up to $35 \%$ after the initial infection and $65 \%$ after a second recurrence. ${ }^{133}$ FMT has been shown to have a remarkable efficacy in treatment of recurrent $C$. difficile colitis with success rate of $90 \%$, compared to $26 \%$ for 
vancomycin. ${ }^{134-136}$ In addition, therapeutic strategies aimed at modifying the intestinal milieu in hopes of reducing pathogenic bacteria virulence hold promise. As an example, taking into consideration the importance of local phosphate abundance for suppression of microbial virulence activation, our laboratory developed a phosphorylated high-molecular weight polyethylene glycol (Pi-PEG) as an anti-virulence therapeutic. When administered orally, Pi-PEG is capable of embedding inorganic phosphate into the intestinal environment and suppressing virulence activation of pathogens across several cellular and animal models, and across several pathogens and pathogen communities. ${ }^{137,138}$

\section{Conclusion}

As our knowledge of the human intestinal microbiome is expanding, we are becoming more equipped to better understand the complexity of the host-microbiome interactions in critical illness and sepsis. The promise of novel therapeutic strategies aimed at restoring and maintaining the healthy microbiome throughout the hospitalization is becoming more tangible.

\section{Microbiome and Anastomotic Leak}

Anastomotic leakage is the most devastating complication of gastrointestinal surgery. The sequelae of a leak are well described and include increased mortality due to septic complications, anastomotic strictures and fistulae, increased rates of cancer recurrence and poor quality of life, among others. ${ }^{139-141}$ When a leak occurs, intraluminal contents of the bowel, such as succus, stool, and bacteria, are given entry into the sterile abdomen, resulting in abdominal pain, fever, and septic shock. ${ }^{142}$ This morbidity translates to increased length of hospital stay and a significant mortality risk. ${ }^{139,143}$ Leaks are particularly prevalent after resection in high-risk areas, such as the esophagus and the rectum. ${ }^{144}$ Although these areas are known to have higher rates of anastomotic leakage, the reason for this remains unknown. ${ }^{145}$ As a result of this persistently high leak rate after rectal procedures, many surgeons choose to divert the enteric stream via ileostomy or colostomy to decrease the clinical mal-effects of anastomotic leakage. ${ }^{146}$ However, this procedure only mitigates the sequelae of leak; it has no preventative effect. Subsequently, diverted patients require reoperation at least six weeks later for takedown of the diverting stoma, another surgical procedure that itself is susceptible to anastomotic leakage. As such, many patients never have their stoma reversed, between $19-40 \%$ in varying series. ${ }^{147,148}$ In addition, those who suffer from anastomotic leak experience subsequent poor anorectal function secondary to pelvic fibrosis. ${ }^{149,150}$

Defining anastomotic leak in a clinical context is no simple task as there is no consensus on the criteria for the diagnosis in patients. ${ }^{151}$ In a systematic review of 97 studies investigating leakage after gastrointestinal anastomoses, Bruce et al. found 56 distinct definitions of leak. ${ }^{152}$ Through that lens, it is easy to understand the context in which the reported leak rate varies from 1-24\%. ${ }^{142}$ Despite years of dogmatic teaching that technical factors are the cause, surgeons remain unable to predict which patients will leak, and the pathophysiology by which leaks occur remains unknown. ${ }^{145,153}$ Increasing evidence suggests that the 
intestinal microbiome changes at the site of a healing anastomosis may have a profound effect on the clinical outcome.

\section{The Microbial Hypothesis of Anastomotic Leak}

The microbial hypothesis of anastomotic leak is greater than 60 years old. In 1955, Cohn and Rives at Louisiana State University rescued dog bowel anastomoses that had been rendered ischemic from ligation of the mesentery by instilling intraluminal topical antibiotics at the site of the anastomoses and preventing the near-100\% leak rate observed in the negative controls. ${ }^{154}$ A similar study was performed in the 1980 s, in which rats undergoing mesenteric vessel ligation that were treated with intraluminal antibiotics were protected from anastomotic leak. ${ }^{155}$ In the 1990s, a German group compared the effect of oral antibiotics (polymyxin, tobramycin, vancomycin, and amphotericin B) to placebo on anastomotic leakage after total gastrectomy. In their randomized, double-blinded, prospective trial, the authors reported a statistically significant decrease in the rate of anastomotic leakage in the antibiotic treated group (10.6\% control versus $2.9 \%$ antibiotic group, $\mathrm{p}<0.05) .{ }^{156}$

Bacteria present at the anastomotic site may respond to the stress of surgical injury with activation of virulence pathways that result in derangements of the healing process. Our laboratory has shown that exposing anastomotic tissues to pathogenic bacteria such as Pseudomonas aeruginosa leads to selection of a virulent phenotype within the bacterial population, causing the certain strains to increase production of an enzyme with collagendegrading activity, resulting in an anastomotic leak. ${ }^{62}$ Further work using 16S rRNA analysis of the microbiome of leaking tissues in rats demonstrated a nearly 500-fold increase in the presence of Enterococcus species in the anastomotic tissue. ${ }^{107}$ Phylogenetic analysis of the Enterococcus genome demonstrated that the GelE gene expression, which produces the collagen degrading enzyme gelatinase, is predominant in the Enterococcus species present at leaking anastomotic tissues. High collagenase-producing Enterococcus introduced to sites of healing anastomotic tissues led to a higher rate of leakage in rats. Only with the use of local antibiotics (i.e topical antibiotics given via enama) was leak prevented. ${ }^{63}$ In the same study, systemic administration of antibiotics (a second-generation cephalosporin, in line with national recommendations for surgical antibiotic prophylaxis) failed to decontaminate the anastomotic site of the same pathogenic bacteria. In fact, other studies have shown a bloom in Enterococcus related to systemic administration of secondgeneration cephalosporins. ${ }^{63,157,158}$

An investigation of the fecal microbiota of patients before and after colorectal surgery for cancer revealed that Enterococcus faecalis and Pseudomonas aeruginosa were the dominant pathogens present after surgery, with a several log-fold increase over the post-operative recovery period. ${ }^{159}$ Similarly, other studies have shown that PCR-detection of Enterococcus in drain fluid after colorectal surgery correlated with those patients that developed anastomotic leakage. ${ }^{160}$

From the 1950s until the 1980s, mechanical bowel preparation with oral antibiotics was the standard of care prior to elective colorectal resection. ${ }^{161}$ Despite numerous randomized trials 
demonstrating the efficacy of oral antibiotics after mechanical bowel preparation, the use of intravenous antibiotics at the beginning of surgery supplanted oral antibiotics. By the 1990s, most surgeons in the United States did not routinely prepare patients for surgery using oral antibiotics. ${ }^{162}$ Currently, there is renewed interest in the United States regarding the use of bowel preparation and oral antibiotics to prevent anastomotic leakage. Matheson et al. performed a multicenter randomized trial with 120 patients undergoing elective colorectal surgery evaluating the role of pre-operative oral antibiotics, in this case oral neomycin and metronidazole. They reported reduced anastomotic leakage (11.9\% in controls, $0 \%$ in antibiotic group, $\mathrm{p}<0.02$ ) as well as decreased rates of superficial wound infection and sepsis. ${ }^{163}$ Further study into the effect of this therapy on the microbiome will be needed before this practice is adopted widely.

\section{Conclusion}

When taken together, the above data from animal and human studies suggest that commensal microbiota subjected to stress of intestinal resection and anastomosis along with other stresses of surgery (prophylactic antibiotics and opioids) may selected species present among the normal commensal microbiota (i.e Enterococcus, Pseudomonas) to express a more aggressive, tissue-destroying phenotype that plays a key and contributory role in the pathogenesis of anastomotic breakdown and clinical leakage. As this hypothesis is more rigorous confirmed in large patient trials, the path forward for novel strategies to prevent leak can be implemented and the routine use of ileostomy avoided.

\section{Microbiome and Cancer}

That certain environmental exposures increase risk for cancer is a well-understood concept. Ultraviolet light is a risk factor for skin cancer; tobacco smoke infamously has been implicated as a risk factor for many forms of cancer, beyond the direct exposure to toxins in the lung. Yet people without identifiable risk factors frequently fall victim to these same diseases. As developments in the control of infectious disease and improvements in hygiene and diet have allowed us to live longer, millions of people annually are diagnosed with cancer. ${ }^{164}$ Now, more than ever, it is imperative for us to gain understanding of the causes and means of preventing this devastating disease. One of the most intimate and ubiquitous exposures remains a relative mystery in its relationship to cancer: the microbiome. In this golden age of discovery of the world around us, the time has come for a greater understanding of the contribution of this substantial exposure to the pathophysiology of cancer.

\section{Normal Host-Microbiome Relationships}

The human body has evolved to maintain a delicate and co-dependent balance with its microbial partners. Several mechanisms exist in order to regulate both the population of the microbiome, and maintain immune tolerate to its presence. ${ }^{165,166}$ Elements of this include an intact epithelium, immune surveillance of bacterial invasion, and organ-specific specialized functions. These include the prohibitively low $\mathrm{pH}$ of the stomach, the mucus in the gut, and secretion of antibacterial molecules by keratinocytes in the skin. ${ }^{167}$ 
The gut, being the host site to the overwhelming majority of the human microbiome, is perhaps the best-equipped organ for microbial regulation. In addition to the aforementioned chemical barrier, the gut contains specialized cells that inactivate potentially invasive bacteria: Paneth cells that can secrete antimicrobials and gut-specific plasma cells within Peyer's patches that secrete of immunoglobulin A (IgA). ${ }^{168-170} \operatorname{IgA}$ limits the host's interaction with both pathogenic as well as commensal microbes. Additionally, the microbiome itself serves as a further barrier against bacterial infection. Clostridium difficile, well known to be an common member of the healthy microbiome, only causes disease when it is no longer counter-balanced by the normal microbiota, which may be eliminated by a course of antibiotics. ${ }^{171}$ Under normal circumstances, the healthy diversity of the gut microbiome provides competition for resources, and thus maintains a balance with pathogens. ${ }^{172}$ In addition, commensal bacteria may respond to the stress of competition by further limiting bacterial growth through the secretion of bacteriocins or antibiotic molecules. ${ }^{173}$

Despite such intricate, co-evolved mechanisms of regulation of the human-bacterial interaction, several investigators have suggested that the same mechanisms which are responsible for microbial detection and immune tolerance may ultimately promote inflammation, inhibit apoptosis and cell senescence and thus promote cancer. ${ }^{165,174}$ Below, we will outline these mechanisms, as well as other interactions with the microbiome that promote tumorigenesis.

\section{Carcinogenesis and the Microbiome}

\section{Perturbations of the Epithelial Barrier}

Much knowledge has been generated over the recent decades to elucidate specific genomic alterations associated with cancer. When considering the added contribution of the microbiome, an obvious question raised is "which came first?" Do genetic mutations lead to dysbiosis or does dysbiosis lead to genetic alterations? Some evidence suggests that certain mutations may predispose the host to a loss of balance with the microbiome. It is likely that altered tumor metabolism or oxygen tension are environmental factors which may be favorable for some microbes to thrive. ${ }^{175}$ Examples of this are epithelial tumors with mutations in proteins responsible for the epithelial barrier function. ${ }^{176}$ Mutations in Ecadherin may lead to dysfunction of tight junctions in the mucosa, which in turn leads to increased bacterial translocation and a resultant increase in tissue inflammation. ${ }^{177}$ Additionally, this barrier dysfunction may allow for the introduction of bacterial antigens not previously seen by the host, triggering inflammation and carcinogenesis. ${ }^{165}$ Nucleotidebinding oligomerization domain-containing 2 (NOD2) is a protein responsible for the recognition of bacterial peptidoglycans, which regulates the immune response to both commensal and pathogenic bacteria. ${ }^{178}$ Inactivation of NOD2 has been shown to increase intestinal inflammation, resulting in colitis with subsequent colitis-associated dysplasia. ${ }^{179}$ In studies using transgenic animals, these changes resulted in a significantly altered microbiome. When this microbiome was transplanted to wild-type animals, a similar phenotype of colitis and increased dysplasia risk resulted; conversely, when the microbiome of wild-type animals was transplanted into knockout animals, the risk was attenuated. ${ }^{179} \mathrm{In}$ 
humans, NOD2 has been shown to increase inflammation in the setting of $H$. pylori infection, leading to activation of nuclear factor-kappa B (NF- $\kappa \mathrm{B})$ and increasing the risk of mucosal-associated lymphoid tissue (MALT) lymphoma. ${ }^{180}$

Further evidence of the link between defects in the epithelial integrity and malignancy exists in the context of colon cancer. Mucin-2 (MUC2) is a gene responsible for mucin production throughout the gastrointestinal tract. It has been shown to be missing in human colorectal cancers, but present in adjacent normal tissue. ${ }^{181}$ In fact, transgenic mice lacking the MUC2 gene develop spontaneous colorectal cancers. ${ }^{182}$ In studies of mouse colorectal cancer models, sites of colorectal cancer demonstrate bacterial translocation not present in normal tissue. ${ }^{181}$ Additionally, mice susceptible to colon cancer demonstrate lower rates of cancer when maintained in a germ-free environment. Taken together, these data suggest that in addition to a genetic component resulting in a defective mucosal barrier, bacteria in the tumor microenvironment contribute to carcinogenesis.

\section{Microbes as Immunomodulators}

With recent advent of immunotherapeutics in the arena of cancer treatment, the immune system's role in cancer is increasingly important. ${ }^{183}$ As noted above, immune tolerance is necessary for appropriate balance of the microbiome. However, the microbiome is equally equipped to modulate the immune system in return. ${ }^{184}$ By exposure to various microbes early in life, we develop tolerance; aberrant host-microbe immune responses lead to hypersensitivity or allergic reactions.

In the context of epithelial barrier breakdown, host adaptive immune responses to the microbes and microbe products can affect tumorigenesis as well. Recognition of translocated bacterial proteins such as flagellin and lipopolysaccharide (LPS) by tumor-infiltrating immune cells can lead to the production of tumorigenic cytokines. ${ }^{176,177}$ Specifically, IL-23, IL-17, IL-6, and TNF-a have been implicated as pro-tumor cytokines in colon cancer. ${ }^{175,176,185}$ In addition to NOD2 discussed above, other members of the nucleotidebinding, oligomerization domain (NOD)-like receptor (NLR) protein family are responsible for innate immunity against commensal microbes; their dysregulation plays a significant role in dysbiosis. ${ }^{186}$ Perturbation of these inflammatory responses (and inflammation in general) can also lead to cancer; anti-inflammatory medications such as aspirin are known to prevent colon cancer. ${ }^{187}$ The relationship of inflammation with cancer also manifests in certain contexts in a microbe-dependent manner. For example, transgenic knockout mice lacking transforming-growth factor- $\beta 1$ develop colitis and ultimately colon cancer. Remarkably, this pattern can be prevented in a germ-free environment. ${ }^{188}$

Lipopolysaccharide, a product of gram negative bacteria, is detected by the innate immune system due to activation of toll-like receptors, particularly TLR4. Activation of TLR4 increases inflammation, and is associated with inflammatory states such as colitis. In animal studies inactivation of TLR4 prevents colitis-associated cancers, while constitutively activated TLR4 is associated with increased severity of colitis and colitis-associated cancer. ${ }^{189,190}$ This is corroborated by increased expression of TLR4 in colon cancer samples from patients with ulcerative colitis. Furthermore, TLRs present on macrophages as well as other inflammatory signals (such as TNF or IL-1), can activate nuclear factor- $\kappa \mathrm{B}$ (NF- $\mathrm{kB}$ ) in 
intestinal epithelial cells. ${ }^{191} \mathrm{NF}-\mathrm{\kappa B}$ leads to DNA transcription, and is an important pathway in the tumorigenesis of stomach and colon cancer, among others. Thus, inflammation as a result of the presence of microbes, may be one of several "hits" in the progression toward cancer. ${ }^{192}$

Conversely, microbe-induced immunosuppression can lead to tumorigenesis. Infamously, chronic and systemic immunosuppression by HIV is a risk factor for numerous malignancies, and particularly virus-associated cancers ${ }^{175}$. The global immunosuppression leads to escape of otherwise eliminated viral infections, leading to chronic inflammation and ultimately oncogenesis. Additionally, immunosuppression may lead to dysfunction of antitumor immunity. For example, Fusobacterium nucleatum has been shown to inhibit NK and $\mathrm{T}$ cells by binding the $\mathrm{T}$ cell immunoglobulin and ITIM domain (TIGIT). This leads to an inactivation of these cells' cytotoxic functions and inability to destroy recognized cancer cells. ${ }^{193}$

\section{Diet, Bacteria and Carcinogenesis}

The modern human diet is a complicated and ever-evolving high-risk exposure for cancinogenesis. Evidence suggests that our diet is closely linked to cancer of the gut as well as other organs. ${ }^{176,194}$ Table 1 summarizes notable examples of diet-bacterial interactions discussed further here. A prime example of this relationship recently received great attention, when the International Agency for Research on Cancer released their report implicating processed meats as a major risk exposure for colon cancer. ${ }^{195}$ However, this particular example deserves additional assessment. Of course, carcinogens present in meat as a result of processing procedures pose an obvious risk. More interestingly, however, are the carcinogenic potential of byproducts of meat that are generated during digestion and metabolism by the gut microbiome. Charred meats containing pro-carcinogenic heterocyclic amines are digested by anaerobic colonic bacteria. ${ }^{196}$ These byproducts are believed to be direct mutagens of the colonic mucosa. Additionally, the commensal bacteria

Bifidobacterium longum and lactobacilli appear to inhibit these toxic effects, associating with lower cancer incidence in animal models of heterocyclic-amine-induced colon cancer. ${ }^{197}$ Digestion of nitrates in meat by gut bacteria also results in the production of $\mathrm{N}$ nitroso compounds or NOC. ${ }^{198}$ These are known alkylating agents responsible for DNA damage, and specifically implicated in $K$-ras mutations associated with colorectal cancers. In addition to meats, high protein foods in general are partly digested by gut bacteria, resulting in hydrogen sulfide as a metabolite. ${ }^{176}$ Hydrogen sulfide is believed to increase colonocyte oxidation, and possibly activate mitogenic pathways such as mitogen activated protein kinase (MAPK), leading to dysregulation of the colonocyte cell cycle. ${ }^{196,199}$ In addition to these mechanisms, hydrogen sulfide has been shown to be a direct genotoxic agent leading to DNA damage. ${ }^{200}$

As we will see in a later section, the microbiome is a significant contributor to obesity. Obesity is a known risk factor for several types of cancer. ${ }^{201}$ The connection between the obesity, the microbiome and carcinogenicity is complicated. A high fat diet may be dangerous for more reasons than previously understood. Dietary fat digestion through $7 a-$ dehydroxylation by bacteria results in increased levels of deoxycholate (DCA), a secondary 
bile acid. ${ }^{202}$ Elevated levels of this molecule are associated with hepatocellular carcinoma, colon and esophageal cancers. ${ }^{165}$ In fact, laboratory models of obese mice demonstrate that mice fed a high fat diet are more likely to develop hepatocellular carcinoma than are mice fed a regular diet. In addition, obese mice demonstrate a higher proportion of Clostridium cluster IX species, which are responsible for the generation of DCA; these mice also demonstrate higher levels of circulating DCA. ${ }^{203}$ In fact, when treated with antibiotics targeting Clostridium species, the mice did not develop hepatocellular carcinoma. However, in a mouse model of intestinal cancer due to $K$-ras mutations, a high fat diet led to increased tumor growth independent of obesity. ${ }^{204}$ In addition, in mice fed a normal diet, a fecal transplant from mice fed a high fat diet reproduced the tumor phenotype, while treatment with antibiotics reversed this increased risk.

As colorectal surgeons have long speculated, fiber may be a beneficial component of the diet in more ways than is currently appreciate. Dietary fiber is fermented by bacteria in the colon, resulting in the production of numerous short-chain fatty acids, including butyrate. ${ }^{175}$ Fiber exerts an anti-inflammatory effect on the colonic mucosa. This is due at in part to activation of GPR109a, a receptor for butyrate on colonic macrophages, the activation of which results in the generation of regulatory T cells. ${ }^{205}$ Additionally, short-chain fatty acids may play a role in colonocyte cell cycle regulation. GPR43, a G-protein coupled receptor for short-chain fatty acids, has been found to be reduced or lost in colon cancer compared to normal colon tissue. Restoration of GPR43 expression in vitro, followed by exposure to butyrate, resulted in increased apoptosis of colon cancer cells. ${ }^{206}$ However, these effects may not be generalizable. In a more recent report, high dietary butyrate was found to induce colon cancer transformation in mice with mutations in the common colon cancer-associated genes APC and MSH2. ${ }^{207}$ Based upon these findings, we must exercise caution in generalizing these recommendations to patients, as the exact risk profile may yet depend upon a complex relationship of the microbiome, dietary metabolites, as well as the underlying genetic background of the host.

There are numerous relationships between dietary compounds, the microbiome, and cancer risk, perhaps even those that improve the cancer risk profile. An example of this includes metabolism of flavonoids by Enterococcus faecium and Lactobacillus mucosae strains leading to decreased risk of cancer in populations consuming high amounts of soy. ${ }^{198}$ Thus, byproducts of bacterial metabolism of various components of our diet, as well as bacterial production of toxins as a response to the diet, may modulate the risk associated with other exposures.

\section{Microbes and Endogenous Pro-Carcinogens}

The bacterial metabolism of many endogenous substances can be similarly important. One example discussed above is the increased transformation of endogenous bile acids in the setting of a high fat diet into secondary bile acids such as DCA by gut bacteria. Another example is that of estrogen, a known risk factor for breast and endometrial cancer. ${ }^{176}$ Circulating estrogens are processed in the liver, and excreted either in urine or bile, and thus are exposed to the colonic microbiome. ${ }^{198}$ Once in the intestine, estrogen breakdown products can undergo biochemical processing, such as deconjugation by colonic bacteria, 
and be returned to the circulation. Additionally, dietary estrogen precursors and phytoestrogens can be further metabolized by colonic bacteria to produce biologically active estrogen-mimicking compounds in the circulation. ${ }^{208}$ Conversely, dietary fiber may bind estrogens in the gut lumen and prevent metabolite processing and recirculation. ${ }^{198}$ Similarly, studies in mice have demonstrated that testosterone levels are closely correlated with the gut microbiome. ${ }^{209}$ When the microbiome from male mice is transferred to female mice of the same background, their testosterone levels are markedly increased over controls. This study highlights the complex influence of the body on the microbiome, and the microbiome, in turn, on the body.

\section{Microbes as Inducers of DNA Damage}

While the bacterial relationship with various environmental factors is complex, there is reason to believe that the individual bacterial species themselves may be causative agents of cancer. Studies in germ-free mice are perhaps most revealing of this relationship. When germ-free mice are transplanted with the fecal microbiome from mice with colon cancer, they are at greater risk of developing the disease than those transplanted with the microbiome of mice without cancer in the absence of any other risk factors. ${ }^{210}$ In fact, specific microbes can be associated with both an increased and a decreased risk of colon cancer in the recipient mice. ${ }^{211}$ Additionally, surveys of patients with colon cancer demonstrate markedly decreased diversity of the microbiome. ${ }^{212,213}$ Together, these findings lead us to continue to question whether dysbiosis is the cause or an effect of colon cancer.

One proposed explanation for this paradox may lie in the evolutionary advantage that certain microbes enjoy that allows them to successfully compete for survival by responding to selective pressures within the local microenvironment. ${ }^{175}$ For example, cytolethal distending toxin (CDT) has a subunit, $\mathrm{CdtB}$, that can produce double-stranded DNA breaks in host cells, frequently resulting in cell cycle arrest and cell death. ${ }^{214,215}$ This mechanism allows bacteria to survive by directly destroying host immune cells. However, the collateral damage from this DNA break may also trigger a critical step toward carcinogenesis. Numerous human pathogens express CDT or similar toxins resulting in double-stranded DNA breaks, notably E. coli, H. pylori, and S. Typhi, all organisms that have been implicated in the pathogenesis of stomach, gallbladder and colon cancers. ${ }^{165,216,217}$ Another bacterial product capable of generating double-strand DNA breaks is colibactin. Colibactin induces DNA damage, resulting in cell cycle arrest and ultimately apoptosis of eukaryotic cells. Several members of the microbiome express colibactin, particularly in the family

Enterobacteriaceae. ${ }^{218}$ E. coli group $\mathrm{B} 2$ is known to express a genomic island, termed pks, encoding genes including colibactin. Contact with this $p k s^{+} E$. coli strain results in doublestrand DNA breaks in human cells. ${ }^{219}$ In IL-10 deficient mice, susceptible to colitis and colon cancer, $p k s^{+} E$. coli was found at a higher concentration in mice with active colitis and colon cancer, while deletion of this gene island resulted in decreased rates of both. ${ }^{220} \mathrm{In}$ addition, transfer of the microbiome into germ free mice with susceptibility for colitis leads to higher colonization by $\mathrm{pks}^{+} \mathrm{E}$. coli, suggesting that inflammation within the host contributes to selection of these deleterious bacteria. ${ }^{221}$ Evaluation of tissue samples of patients with colon cancer compared to patients with diverticulitis as controls revealed a significantly higher rate of colonization with B2 group E. coli in patients with cancer. ${ }^{222}$ 
Further assays revealed that the genotoxic genes located in the $p k s$ island were functionally active in the cancer tissues.

Generation of reactive oxygen species is another mechanism of DNA damage resulting in cancer formation. Bacteroides fragilis is a potentially pathogenic member of the gut microbiome, capable of producing Bacteroides fragilis toxin (Bft). This toxin results in the generation of reactive oxygen species and activation of the host cell stress response, leading to DNA damage. This may lead to downregulation of the tumor suppressor E-cadherin, and upregulation of the c-Myc oncogene, causing increased cell proliferation. ${ }^{223,224}$ Additionally, laboratory models suggest that the toxin triggers IL-17-mediated inflammation; when IL-17 is blocked, animals infected by Bft-expressing B. fragilis develop fewer colonic tumors. ${ }^{225}$ Investigation of Bft expression in samples from patients with colon cancer revealed a significantly higher level of $\mathrm{Bft}$ (in both tumor and adjacent normal tissue), as compared to healthy controls. ${ }^{226}$ Thus, colonization by toxin-producing $B$. fragilis may be a risk factor for colon cancer. However, colonization alone is insufficient to cause cancer; the microenvironment must shift in favor of supporting the presence and growth of $B$. fragilis, which can exert a pro-carcinogenic effect when no longer counter-balanced by beneficial microbes. ${ }^{227}$ Other bacterial molecules are also capable of signaling cellular growth pathways via E-cadherin. F. nucleaum, another known member of the normal human microbiome, has been associated with colonic adenomas and tumors. ${ }^{228,229}$ This may be due to its expression of the FadA molecule, which allows bacterial adhesion to human tissue. FadA binds to E-cadherin on the surface of normal cells, causing cleavage of $\beta$-catenin. ${ }^{230}$ The downstream effects of $\beta$-catenin activation include increased expression of oncogenes and inflammatory genes. Similarly, AvrA, a protein secreted by $S$. typhi during chronic infection, has been shown to activate $\beta$-catenin. ${ }^{231}$ This property of $S$. typhi may explain its relationship with colon and gallbladder cancers. ${ }^{232-234}$

\section{Organ-Specific Considerations}

\section{Specific Microbe-Cancer Relationships}

Several direct microbe-cancer relationships have been observed; these are summarized in Table 2. The intestine has significant direct interaction with the microbiome. As many of the above sections have described, direct toxicity to cells in contact with potentially dangerous microbes increases the risk for tumorigenesis. Perhaps the high concentration of microbes in the large intestine explains the higher incidence of cancers there as compared to the small intestine. ${ }^{165}$ Certain risk factors, such as epithelial barrier function defects may lead to the proliferation of deleterious microbes over the usual commensal flora, further increasing an individual's risk of cancer. Another example of this step-wise pathway toward cancer is inflammatory bowel disease. ${ }^{235}$ This has been studied using IL-10 deficient mice that mimic an inflammatory bowel disease phenotype. Mice predisposed to inflammation carry a significantly different microbiome from wild-type mice, characterized by decreased diversity and increased concentrations of Enterobacteriaceae. By manipulating the microbiome, the rate of carcinogenesis can be attenuated. ${ }^{236}$ In fact, studies of patients with inflammatory bowel disease demonstrate decreased diversity of the gut flora, irrespective of the NOD2 status of the patient, which was noted previously as a risk factor for epithelial barrier 
dysfunction. ${ }^{237,238}$ Specifically, invasive $E$. coli species have been associated with colitis and colon cancer in the setting of inflammatory bowel disease. ${ }^{239,240}$

In recent years, $H$. pylori has been implicated as a causative agent in the pathophysiology of gastric cancer. ${ }^{241}$ Colonization of the stomach by H. pylori is an overwhelmingly common occurrence worldwide. Chronic infection leads to gastritis, hypochlorhydria, gastric atrophy, gastric ulcers and ultimately gastric cancer. ${ }^{242}$ By its effect on the mucosal barrier of the stomach, H. pylori may also lead to overgrowth of the stomach by other deleterious bacteria, leading to increased risk of cancer due to the metabolism of dietary nitrates by such microbes. ${ }^{165,243,244}$ Interestingly, observational data suggests that there is a decreased risk of esophageal cancer among patients with $H$. pylori. As a corollary to this observation is the finding that esophageal cancer prevalence has increased since widespread treatment for $H$. pylori has been implemented. ${ }^{245}$ The protective effect may be due to the hypochlorhydria, resulting in decreased acid reflux and decreased caustic damage to the lower esophagus.

Microbial-mediated carcinogenesis however is not just limited to bacteria. Human papilloma virus is an extremely common microbe, silently infecting millions of people worldwide. Several strains of the virus, particularly HPV16 and HPV18, have been identified as causative factors leading to cervical, anal and oropharyngeal cancers. ${ }^{246}$ HPV replication relies upon several key proteins, called "early proteins," of which E6 and E7 are categorized as oncoproteins. To aid in viral replication and survival, E7 binds pRB, resulting in transcription of proteins needed for DNA replication, and E6 leads to degradation of p53, thus interfering with cell apoptosis. By doing so, the viral proteins begin the process of tumorigenesis in infected tissues. ${ }^{247}$ Other viruses are similarly classified as human carcinogens, most notoriously the hepatitis viruses, leading to cirrhosis and hepatocellular carcinoma. ${ }^{248,249}$

\section{Organs without a Microbiome}

The gut is the primary home for our microbiome. Most interactions with carcinogenic microbes are direct and organ-specific. However, other types of cancer may be affected by microbiomes and microbial products, despite lack of an appreciable direct microbial contact. ${ }^{165}$ For example, observational evidence previously suggested that antibiotic use is associated with breast cancer. ${ }^{250}$ In fact, there may be a detectable microbial community within human breast milk. ${ }^{251}$ More recently, classification of microbial DNA in breast cancer biopsy samples revealed a significantly lower and different bacterial load compared to normal tissue. ${ }^{252}$

There is evidence that pancreatic cancer may be another example of microbiome related cancer. In the setting of pancreatitis, exposure to LPS may accelerate pancreatic tumorigenesis. ${ }^{253}$ Additionally, variations in the oral microbiome have been associated with increased risk of pancreatic cancer. ${ }^{254}$ While this observation is poorly understood, one hypothesis is that the inflammatory state of the patient with pancreatic cancer may allow for colonization by these microbes; therefore, classification and characterization of the oral microbiome may allow earlier detection of pancreatic cancer. Another potential mechanisms by which the oral microbiome contributes to carcinogenesis is via activation of toxins, such 
as alcohol and carcinogens in cigarette smoke with their resultant exposure to the upper GI tract. $^{255}$

As a result of breakdowns that can occur in the epithelial barrier, various bacterial products can be introduced to the systemic circulation. This may be yet another mechanism by which there is exposure of distant organs to the microbiome. These molecules are termed "microorganism-associated molecular patterns," or MAMPs. ${ }^{165}$ One such MAMP is DCA, discussed previously, which increases in the gut as a result of a high-fat diet or obesity and which is associated with hepatocellular carcinoma. ${ }^{200,203,204}$ Another such molecule is LPS produced by gram negative bacteria, which can bind to human cells via toll-like receptor 4 (TLR4). In the setting of existing liver damage, activation of TLR4 has been shown to potentiate hepatic fibrosis, cirrhosis and hepatocellular carcinoma. ${ }^{256-258}$

Another unexpected site of bacterial carcinogenesis is the lung. The lung has recently been shown to harbor a significant microbiome. Studies of patients with COPD have revealed a significantly altered lung microbiome compared to the lungs of healthy controls. ${ }^{259}$ This difference may be the result of the alteration in the organ due to the disease itself, or due to the higher use of steroids and bronchodilators among patients with COPD. Infections in the setting of COPD may exacerbate the disease and may lead to chronic inflammation. ${ }^{260} \mathrm{In}$ studies in a model of animals susceptible to lung cancer, a higher incidence of lung cancers was demonstrated in rats with chronic respiratory infection, compared with germ-free and specific-pathogen-free controls. ${ }^{261}$ Additional studies in mice suggest that this effect may be due to exposure to LPS. ${ }^{262}$

\section{The Microbiome and Cancer Treatment}

\section{The Microbiome as a treatment for Cancer}

Despite the numerous examples of microbes as deleterious agents in the pathway to cancer, we have seen several examples of beneficial effects of microbes and their products. A connection between bacterial infection and cancer regression was noted over 300 years ago. ${ }^{263,264}$ Later, a New York surgeon in the 1890s, Dr. William Coley, noted spontaneous cure of sarcoma in his patients who simultaneously suffered from erysipelas. ${ }^{265}$ After disastrous results from injection of $S$. pyogenes into cancer patients in the pre-antibiotic era, Dr. Coley refined his treatment by using heat-killed bacteria, now known as "Coley's toxin." More recently, similar observation in patients after glioblastoma resection suggest a survival benefit for patients who suffer post-operative infection. ${ }^{266}$ These findings are difficult to reproduce consistently; however, the concept of using bacterial products to induce immune responses against cancer is widely utilized. ${ }^{183}$

Among the currently used "Coley toxins" is BCG for the treatment of non-muscle invasive bladder cancer. BCG, or Bacillus Calmette-Guérin, is an attenuated strain of Mycobacterium bovis. The strain was developed in the quest for an effective vaccine for tuberculosis. Due to observations of the effect of the vaccine on subsequent immune responses, it was applied as a therapy for cancer. ${ }^{267}$ Today, it remains a useful tool for localized bladder cancer, due to its induction of a tremendous local immune response. ${ }^{268}$ Similarly, Listeria monocytogenes has 
been used as an anti-tumor vaccine and has shown promise in animal studies due also to its ability to stimulate the innate and adaptive immune systems. ${ }^{269,270}$

As we saw previously, dysbiosis may be responsible for the "first hit" in the process of carcinogenesis. In fact, detection of dysbiosis has been proposed as a screening test for early colon cancer. ${ }^{271}$ It seems logical that a return of eubiosis may reverse some of these harmful effects. Lactobacilli are common members of the microbiome, and are most often beneficial. Bioengineered strains of Lactobacilli can engage the immune system and reverse colonic inflammation and even lead to regression of established polyps in mice. ${ }^{272,273}$ Other genetic alterations of members of the gut microbiome have been used to decrease inflammation by overexpression of antioxidants. ${ }^{274}$

Just as diet can lead to the production of harmful bacterial products, it can also produce beneficial results. While "probiotics" may be used to introduce beneficial bacteria into the microbiome, "prebiotics" can be used to promote the growth of favorable members of the microbiome. ${ }^{275}$ These include indigestible foods, such as fiber, inulin and lactulose. These have been shown to increase the proportion of Bifidobacteria and Lactobacilli in the gut microbiome, which in turn can result in decreased aberrant crypt foci in mouse studies. ${ }^{276} \mathrm{~A}$ direct relationship between these bacteria and decreased cancer risk has not yet been established.

While it is tempting to develop therapeutic strategies to eliminate certain bacteria as an attempt to reverse dysbiosis using antibiotics, this approach carries major risks. With known pathogens, such as $\mathrm{H}$. pylori, targeted bacterial eradication is associated with a decreased cancer risk. However, it is known that non-targeted antibiotic therapy carries the unwanted risk of eradication of beneficial bacteria. This leaves patients at risk for opportunistic bacterial infections, such as $C$. difficile, and makes them vulnerable to infection by multidrug resistant species. With the recent rise of fecal transplantation for the treatment of severe $C$. difficile colitis, it seems logical to hypothesize that this may be an effective tool for fighting "procarcinogenic" dysbiosis. In fact, fecal microbial transplantation has been reported as an adjunct tool for the treatment of severe inflammatory bowel disease. ${ }^{277}$ Until we know the exact pathogens responsible for other disease processes to allow specific treatment, it may be more prudent to focus on targeting specific inflammatory pathways activated by these bacteria or their genotoxins. ${ }^{165}$

\section{The Microbiome as an Adjuvant}

As chemotherapeutic medications are exquisitely toxic agents, it is not surprising that they exert an effect on the microbiome. In the setting of allogenic hematopoetic stem-cell transplantation, the gut-associated microbiome undergoes significant changes, due in part to damage of the intestinal mucosa. Reduced gut microbiome diversity has been reported as a predictor of mortality after stem-cell transplantation. ${ }^{278}$ There is a similar loss of microbiome diversity following bone marrow transplantation. ${ }^{279}$ Studies of bone marrow transplantation models demonstrate that reintroduction of Lactobacillus species reduces intestinal inflammation and protects against intestinal graft versus host disease. 
Various chemotherapeutic drugs interact with the microbiome, with effects resulting in altered drug responses or side effect profiles. Camptothecin and its analogues (topotecan, irinotecan) target human topoisomerase I, specifically affecting rapidly-dividing cells. Irinotecan in particular is capable of causing severe diarrhea. ${ }^{280}$ It undergoes glucuronidation in the liver, and is then excreted into the GI tract as an inactive metabolite. However, $\beta$-glucuronidase enzymes produced by commensal microbes are capable of reactivating this into its active form, thus leading to gastrointestinal toxicity. Therefore, inhibition of this enzyme may prevent or attenuate the gastrointestinal side effect. Cyclophosphamide also causes intestinal toxicity, which leads to bacterial translocation, immune stimulation and thus activation of Th17 cells. These have been shown to be necessary for the efficacy of cyclophosphamide as an anticancer treatment. ${ }^{281}$ The microbiome also assists in the therapeutic efficacy of oxaliplatin by modulating the function of myeloid immune cells, making them capable of generating a larger oxidative reaction in response to the drug. ${ }^{282}$

As immunotherapies are showing great promise in cancer treatment, the relationship of the immune system with the microbiome becomes increasingly important. As we discussed previously, commensal and pathogenic microbes are capable of having enormous effects on the immune system. In fact, Bacteroides species appear to be crucial in the host response to anti-CTLA-4 therapies. ${ }^{283}$ Bacteroides species have been shown to become enriched in the microbiome as a result of anti-CTLA-4 therapy. Additionally, germ-free mice appear resistant to anti-CTLA-4 therapy, a finding that can be reversed by microbial transplantation. In other studies, the presence of the commensal microbe Bifidobacterium in the gut has been shown to be required for the therapeutic efficacy of checkpoint blockade with anti-PD-L1 antibodies in mice harboring melanoma cells. ${ }^{284}$ These findings suggest that the intestinal microbiome governs and regulates the immune system in a manner that influences the efficacy of immunotherapy.

Harnessing the relationship of bacteria with epithelial host cells also has therapeutic potential. Understanding the mechanisms of bacterial carcinogenesis can be used to inform novel strategies to selectively deliver toxic molecules to tumors using attenuated microbes. ${ }^{285}$ Additionally, elucidation of the mechanisms utilized by microbes to survive on the epithelial tissues can also inform novel therapeutic strategies. An example of this is the type III secretion system (T3SS), which is a molecular syringe used by bacteria to deliver proteins into human cells. ${ }^{286}$ Utilizing such a system may allow targeted drug delivery into tumor cells. In fact, engineered microbes have been proposed as therapies targeting specific intracellular tumorigenic pathways. ${ }^{287,288}$

\section{Conclusion: The Future of the Human Microbiome in Cancer Research and Treatment}

Humans share a history of co-evolution with their microbial partners over ever changing environments and over the long course of human progress. There are countless ways in which these co-evolved mechanisms are helpful, ways in which they are harmful and tipping points in at which imbalances cause cancer. Tremendous advances are being made in the 
understanding of the molecular mechanisms of tumorigenesis. However, these cannot be fully understood without the context of the human body, including consideration of the contribution from the human microbiome. ${ }^{165,289}$ All aspects of human life and progress affect the microbiome and the microbiome affects all aspects of human biology. Future cancer research must incorporate the influence of the microbiome on all aspects of cancer from its oncogenic potential to its response to chemotherapeutic agents.

Although the influence of the microbiome on intestinal tumorigenesis seems obvious, its contribution to the pathogenesis of extra-intestinal cancers remains poorly understood. As previously noted, bacterial products introduced in the circulation can directly damage nonintestinal cells (e.g. DCA in liver cancers, LPS in pancreatic cancer), modulate immune cell behavior to affect other organs, ${ }^{176,283}$ and induce inflammatory states favorable for the development of cancer. Extra-intestinal microbiomes, while relatively small in comparison to the gut microbiome, may play an important but underappreciated role in these processes. As Dr. Coley observed over 100 years ago, microbiomes on the skin appear to contribute to an immune response which can be harnessed for cancer treatment. ${ }^{265}$ Other microbiomes, such as in the lung, mouth, and genitourinary tract may play similarly important roles. ${ }^{165,259}$

Today, understanding the mechanism by which diet affects the microbiome and human health is most pressing. Diet has the potential to enrich and select for certain bacteria and shape the overall composition and function of the microbiome. High fiber diets appear to be most beneficial for the selection of beneficial microbes. ${ }^{275}$ Addition of other dietary components may select for microbes capable of enhancing cancer. ${ }^{283}$ Further careful evaluation of diet and the environmental factors which favor selection of bacteria capable of producing antioxidant and other anti-tumor compounds may advance the understanding and treatment of cancer.

\section{Microbiome and Obesity}

Obesity has become a global health epidemic. Between 1980 and 2014, the worldwide prevalence of obesity more than doubled, resulting in over 1.9 billion adults being overweight (BMI>25) and over 600 million obese (BMI>30). ${ }^{290}$ In the United State alone, a third of the adult population and $17 \%$ of adolescents are obese. ${ }^{291}$ Leading causes of preventable death are linked to obesity, including diabetes mellitus, hypertension, cardiovascular disease, and certain types of cancer (breast, colon and endometrial). ${ }^{292,293}$ The pathophysiology of obesity is associated with host genetics and behavioral factors such as diet and physical activity. ${ }^{294-296}$

However, it is becoming increasingly clear that in addition to host factors, the intestinal microbiome plays a critical role in the pathogenesis of this complex disease process through alterations to the host energy metabolism, fat storage, and resultant body morphology. 297 Mechanisms through which gut bacteria are able to affect host weight are related to differential energy extraction from the diet, release of bacterial metabolites and modulation of inflammation. This section focuses on the available evidence linking the gut microbiome to obesity and its resultant health complications; the effect of bariatric surgery on the microbiome will also be discussed. 


\section{Altered Gut Microbiome of the Obese}

The phenotype of obesity is correlated with derangements in the makeup of the intestinal microbiome. Multiple studies suggest that the proportion of Bacteroidetes and Firmicutes in the intestinal lumen may play a role in the pathophysiology of obesity. Comparative analysis of the microbiota of leptin deficient (obese) mice and their lean counterparts fed the same diet showed a 50\% reduction in the abundance of Bacteroidetes and a proportional increase in Firmicutes in the obese animals. ${ }^{298}$ Other animal models of obesity corroborate this finding. ${ }^{299}$ Comparable observations have been made in human studies. Using 16SrRNA analysis, Ley et al. studied the intestinal microbiome of 12 obese individuals randomly assigned to either a fat-restricted or to a carbohydrate-restricted low-calorie diet over a one year period. The authors showed that the baseline relative proportion of Bacteroidetes was dramatically decreased in obese people when compared to lean controls; however, with weight loss on either type of low calorie diet, the proportion of Bacteroidetes was increased to resemble that of the lean individuals. ${ }^{300}$ Looking at the differences in the composition of the microbiome in monozygotic and dizygotic twin pairs concordant for body weight, Turnbaugh et al. confirmed that the gut microbiome of obesity is associated with reduced bacterial diversity (specifically decrease of Bacteroidetes) and enrichment in genes involved in energy metabolism. ${ }^{301}$ Kalliomaki et al. compared the intestinal microbiome composition of infants and noted that specific differences in the microbiome composition were predictive of overweight versus lean body type at age 7.302 The alterations of the gut microbiome in obesity are not constrained to the large intestine. Obesity has been shown to be associated with specific changes in the composition of the salivary microbiome. ${ }^{303}$ Goodson et al. showed that a single bacterial species Selenomonas noxia was present in $98.4 \%$ of overweight women suggesting that salivary bacteria may play a role in the pathophysiology of obesity and that a specific salivary microbial signature could be associated with the overweight condition. Evidence is plentiful that the intestinal microbiome composition differs with body morphology.

\section{Is there a Causal Link between Gut Bacteria and Obesity?}

A great deal of what is known today regarding how the gut microbiome shapes energy metabolism and body phenotype has been developed from studies performed in germ-free animal models. Animals raised in an environment completely devoid of microbes have been shown to be resistant to gaining excess weight despite consuming a fat- and sugar-rich Western diet. ${ }^{304}$ This work published by Bäckhed et al., revealed that the resistance of germfree animals to obesity is associated with an increase in fatty acid oxidation. However, germfree mice devoid of a lipoprotein lipase inhibitor Fiaf (normally suppressed to some degree by the microbiota) lose resistance to weight gain and are able to acquire the obese phenotype. Interestingly, germ-free mice colonized by cecal contents harvested from conventionally raised animals experienced a $60 \%$ increase in body fat content within 14 days with increased absorption of monosaccharides and induction of de novo hepatic lipogenesis, despite reduced food intake. ${ }^{305}$ Microbiota transplantation from a diet-induced obese donor mice to lean germ-free recipient mice promoted a greater degree of fat deposition compared to transplants from lean controls. ${ }^{306}$ Furthermore, a humanized mouse model of transplantation of human fecal microbial communities into germ-free mice and noted that 
exposure of these mice to a Western diet led to a rapid shift in the structure of the microbiota along with alterations in its gene expression and metabolic pathways that led to increased adiposity. ${ }^{307}$ Interestingly, this metabolic phenotype was transmissible to a second generation of animals via fecal transplant. Taken together, these findings suggest presence of a causal link between structurally and functionally different gut microbiome compositions and body phenotype.

\section{Gut Bacteria are Critical in Regulating Host Metabolism}

The bacteria contained within the human intestine play an essential role in dietary energy harvest. ${ }^{65,308}$ Gut bacteria assist the host with breakdown of otherwise non-digestible dietary polysaccharide substrates such as resistant starch and non-starch polysaccharide components of fiber. End products of bacterial fermentation such as monosaccharides and short-chain fatty acids (butyrate, propionate and acetate) are easily assimilated by the host and used for de-novo glucose synthesis or energy storage in the form of lipid. ${ }^{309,310}$ Shortchain fatty acids, specifically butyrate, comprise up to $70 \%$ of the fuel used by the colonocytes. ${ }^{103,311}$

The obese phenotype may be correlated with a bacteria-associated increase in energy harvest efficiency. ${ }^{301}$ Using metagenomic analysis, Turbaugh et al. showed that the leptin-deficient obese mouse microbiome is enriched in genes involved in energy harvest when compared to their wild-type lean counterparts. ${ }^{65}$ Microbiota transplantation from leptin-deficient obese mice into the gut of germ-free animals resulted in a statistically significant increase in percent body fat when compared to germ-free mice that received fecal transplant from lean animals. Similar findings have been seen in human microbiome research. In comparing the short-chain fatty acid content of the human gut microbiome of lean and obese individuals, Schwierz et al. reported that the total amount of short chain fatty acids was higher in the obese subjects with excess of propionate when compared to the lean subjects. ${ }^{312}$ In a study performed by Santacruz et al., adolescents subjected to a calorie-restricted diet and increased physical activity over a 10 week period of time diverged into two groups, those who lost $<2 \mathrm{~kg}$ or $>4 \mathrm{~kg}$ of weight. Adolescents who lost more weight had a distinct microbiome composition, characterized by lower abundance of Lactobacillus and Bifidobacterium when compared to those resistant to weight loss suggesting that the capacity for weight loss may be a function of our gut microbial fingerprint. ${ }^{313}$

Additional evidence shows that specific bacteria present in the gut determine the efficiency of energy harvest from the diet and in turn the predominant diet type ingested may determine the composition of our intestinal microbiome. For example, mice colonized with Methanobrevibacter smithii are capable of increased dietary energy extraction and weight gain. ${ }^{314}$ Fecal transplant of Bacteroides (phylum Bacteroidetes) and Eubacteria (phylum Firmicutes) together into gnotobiotic mice leads to higher energy extraction than either bacteria alone. ${ }^{315}$ Consumption of an animal-based diet increases the abundance of biletolerant microorganisms that are better equipped to ferment protein (Bacteroides), while decreasing levels of Firmicutes that metabolize dietary plant polysaccharides. ${ }^{316}$ Meanwhile, a decrease in carbohydrate intake in the diet is associated with decreases in specific bacteria better equipped to metabolize carbohydrates. ${ }^{317}$ Taken together, evidence suggests that the 
microbiome of an obese individual may be determined by their diet and therefore be better equipped to harvest energy from this specific diet.

\section{Microbiome and Inflammatory Changes Associated with Obesity}

Obesity has been linked to a low-grade persistent global inflammatory state. ${ }^{318,319}$ Animal models of obesity reveal that the adipose tissue is characterized by increased presence of tissue macrophages with associated increase in the expression of pro-inflammatory cytokines, including TNF-a, IL-1 and IL-6. ${ }^{320}$ This pro-inflammatory state of obesity has been associated with a range of diseases that frequently accompany obesity: insulin resistance, type 2 diabetes mellitus and cardiovascular disease. ${ }^{321-323}$ Furthermore, the chronic inflammation of obesity is associated with defects in immune responses carried out by neutrophils, natural killer cells and T cells. ${ }^{324}$

As seen in the previous sections of this monograph, intestinal bacteria play a critical role in modulation of intestinal and global inflammation. Therefore, it is plausible that changes in the composition and function of the gut microbiome in obesity also contribute to the pathogenesis of the chronic pro-inflammatory state. Cani et al. discovered that a high-fat diet leads to increase in the proportion of gram-negative bacteria in the murine gut with associated increase in circulating lipopolysaccharide (LPS) resulting in a "metabolic endotoxemia"; at the same time, levels of circulating LPS decrease with fasting. The authors further demonstrated that continuous subcutaneous infusion of LPS causes weight gain and insulin resistance at rates equivalent to those of mice chronically fed a high-fat diet. ${ }^{325}$ Higher endotoxin levels in the blood have been associated with 1.8 times increased risk of untoward cardiovascular events and 1.5 times increased risk of development of type 2 diabetes. ${ }^{326-328}$ Furthermore, levels of serum amyloid A protein produced in response to LPS signaling are increased in the obese. ${ }^{329}$ Additionally, a high-fat diet, in addition to altering the composition of the intestinal microbiome, promotes intestinal epithelial LPS absorption in chylomicrons. ${ }^{330}$ To further corroborate these results, loss-of-function mutations in TLR4 as well as downstream adaptor protein Myd88 have been shown to be protective against diet-induced obesity in a mouse model. ${ }^{329,331}$ In support of these findings, physical exercise and associated weight loss were linked to reduced serum LPS, suppressed TLR-4 signaling and improved insulin sensitivity. ${ }^{332}$ Furthermore, concurrent administration of high-fat diet and oral antibiotics (ampicillin, neomycin and metronidazole) to mice not only altered the gut microbiota composition by reducing the levels of Bacteroidetes and Firmicutes, but also reduced circulating LPS levels, fasting glucose, TNF-a, IL-6 and TLR4 activation, consequently improving glucose tolerance. ${ }^{333}$

\section{Effect of Bariatric Surgery on the Gut Microbiome}

Bariatric surgery is currently the most effective and durable treatment of obesity and obesity-related comorbidities such as diabetes mellitus, obstructive sleep apnea, dyslipidemia and hypertension. Bariatric surgery also reduces overall and cardiovascular mortality. ${ }^{334-336}$ Two types of bariatric surgery exist based on the resulting gastrointestinal anatomy: purely restrictive and malabsorptive with restriction. Restrictive procedures reduce the luminal diameter of the stomach without altering the absorptive capacity of the small 
intestine, thereby restricting the amount of food intake. Restrictive procedures include laparoscopic adjustable gastric band (LAGB), vertical-banded gastroplasty (VBG) or sleeve gastrectomy (SG). On the other hand, malabsorptive procedures are designed to reduce the surface area of the intestine available for nutrient absorption through bypass of intestinal segments. In addition, all malabsorptive procedures in use today, such as Roux-en-Y gastric bypass (RYGB) and bilio-pancreatic diversion (BPD) with or without duodenal switch (DS), also employ a form of gastric restriction. ${ }^{337}$

Given the anatomical and physiological changes caused by bariatric surgery, it is not surprising that the community structure of the intestinal microbiome becomes significantly altered after these procedures. Zhang et al. compared the intestinal microbiome structures at a single time point between individuals with normal weight, morbid obesity, and those 8-15 months post RYGB surgery. The abundance of Firmicutes normally seen in the gut, was significantly decreased in individuals post RYGB when compared to both normal weight and morbidly obese individuals; at the same time, a higher proportion of Gammaproteobacteria was seen in the RYGB group, composed mostly of members of the family

Enterobacteriaceae. ${ }^{338}$ A longitudinal study by Furet et al. compared the gut microbiota of 13 lean controls with 30 obese individuals at baseline, 3 months and 6 months after RYGB. Not surprisingly, the baseline microbiome of obese individuals was characterized by a high Firmicutes to Bacteroidetes ratio, which significantly decreased following surgery. ${ }^{339}$ Additionally, the authors noted that certain circulating inflammatory markers (CRP, IL-6) were reduced following RYGB, which was associated with increased abundance of Faecalibacterium prausnitzii, a bacterium known to reduce intestinal inflammation. ${ }^{339,340}$ These findings were further corroborated by Li et al. in a rat model of RYGB, where the Firmicutes to Bacteroidetes ratio was also reduced following RYGB as compared to sham surgery. Interestingly, there was a striking 52-fold increase in the members of phylum Proteobacteria following RYGB, verifying earlier findings of Zhang et al. ${ }^{338,341}$

The underlying mechanisms by which bariatric surgery leads to improvement in obesity and related comorbid conditions have not been fully elucidated. The altered anatomy and physiology of the gut following bariatric surgery along with changes to the dietary intake preferences, energy expenditures, decreased hunger and increased satiation have been suggested and might be mediated by the changing composition of the intestinal microbiome. ${ }^{342}$ For example, due to the shortened absorptive surface area of the small intestine and faster transit time following RYGB, the distal gut is exposed to a higher oxygen tension and increased $\mathrm{pH}$, in effect favoring the fast-growing facultative anaerobic Gammaproteobacteria over obligate anaerobes that normally inhabit the distal gut. ${ }^{338}$ In the future, therapeutic modifications to the already altered post-bariatric surgery gut microbiome may prove to promote even further weight loss and even faster resolution of obesityassociated comorbidities. Actually, evidence already exists to show that probiotic (Lactobacillus) administration in post-RYGB patients reduces bacterial overgrowth and improves weight loss when compared to patients receiving placebo after surgery. ${ }^{343}$ 


\section{Conclusion}

It is increasingly clear that the functional differences of human microbiome contribute to obesity, and in turn, the obese state alters the diversity and function of the gut microbiota. Evidence suggests that alongside host genotype and lifestyle, the gut microbiome is a critical element in the pathophysiology of obesity. These findings suggest that manipulation of community structure and function of the human microbiome may be a useful strategy for regulating energy balance in obese individuals.

\section{Microbiome and Personalized Medicine: The Future}

Given the advance in sequencing technology, proteomics and metabolomics, there is great potential to understand and shape the microbiome to improve human health. One means of doing this is the personalization of medicine in the context of an individual's specific microbiome. ${ }^{344,345}$

In recent decades, there has been a boom in the discovery of genetic and genomic contributions to disease. Of great interest has been the concept of pharmacogenomics, or the understanding of how an individual's genes influence their metabolism of medications. ${ }^{346}$ More recently, we see a rise in interest in pharmaco-metabolomics, or the use of genomic data to predict differences in metabolism and toxicity of drugs. ${ }^{347}$ The gut microbiome, due to its key role in digestion and metabolism, plays a critical role in the way therapeutic drugs are metabolized and thus will dramatically influence their efficacy. ${ }^{348}$ The microbiome influences the metabolism of many common medications, from acetaminophen to digoxin to chemotherapy ${ }^{349-351}$ Identification of specific bacterial enzyme pathways influenced by the microbiome and involved in disease processes can be specifically targeted. ${ }^{352}$

The ability to interrogate both the patients host genome as well as their microbiome will allow for a more holistic view of disease progression in the context of the paradigm of geneenvironment interactions. ${ }^{353}$ Dysbiosis may be corrected by targeted removal of offensive members of the microbiome using delivery systems such as CRISP/Cas9. Use of probiotics, fecal transplantation or correction of the functional disturbance created by their genomic profile may also be possible. ${ }^{354-356}$ Diet can also be utilized as a method of tailoring an individual's microbiome toward eubiosis once the composition and function of a health promoting microbiome is defined.

Antibiotic overuse is ubiquitous in hospitals and increasingly in outpatient settings, agriculture, and livestock. The human microbiome undergoes daily insults from which it must recover. Eliminating this practice and its collateral damage is politically and economically complicated, yet understanding how to manage its untoward effects is needed. Developing new methods to improve microbiome resilience and restoration are being explored by both academic institutions and industry.

One example of this approach is in the treatment of intractable or recurrent Clostridium difficile infection(CDI). Transplantation of fecal microbiota (FMT) from healthy individuals into the intestinal tract of patients with intractable illness has progressed from folklore to clinical trial. ${ }^{357}$ FMT experiments in animal models of CDI have demonstrated recovery of 
microbiome diversity and increased resistance to CDI recurrence. ${ }^{358}$ In clinical practice, FMT remained a last resort therapy until the emergence of convincing randomized clinical trial evidence that fecal microbiota transplant was more effective than conventional antibiotic therapy in the treatment of recurrent CDI ${ }^{359}$ Recovery of intestinal microbiome diversity appears to be the defining characteristic of FMT success. ${ }^{360}$ As exciting as this new therapy is, there remain significant safety concerns for subsequent infection or autoimmunity with transfer of the entire microbiome. ${ }^{357}$ As a result, targeted methods are being developed. Loss of specific bacterial taxa and functions is related to susceptibility to CDI, including depletion of anaerobic populations and loss of bacterial deconjugation of bile salts. ${ }^{361}$ Transplantation of specific bacterial consortia has shown similar efficacy to FMT. ${ }^{362}$ Using intestinal microbiome metagenomic analyses from mouse models and clinical studies, Buffie and colleagues determined that Clostridium scindens, a bile acid 7-dehydroxylating intestinal bacterium, is associated with resistance to CDI. ${ }^{363}$ This approach to restore CDI resistance following antibiotic use is one example in which management of the overuse of antibiotic by microbiome maintenance therapy is possible.

\section{Summary}

As we have seen throughout this monograph, microbes play a key role in both human health, disease, response to surgery and pharmacologic intervention. Advancing the understanding of these complex relationships is in its infancy. Technological advances in analysis, large data management and interpretation of data are rapidly evolving to address disease states which have eluded investigator and clinicians. What has been learned so far, however is both exciting and humbling.

\section{Acknowledgments}

NIH grant 2R01GM062344-13A1

\section{References}

*Complete bibliographic material available from the author on request

1. Cho I, Blaser MJ. The human microbiome: at the interface of health and disease. Nat Rev Genet. 2012; 13(4):260-270. [PubMed: 22411464]

2. [Accessed March 11, 2016] All About The Human Genome Project (HGP). https:// www.genome.gov/10001772

3. Eckburg PB, Bik EM, Bernstein CN, et al. Diversity of the human intestinal microbial flora. Science. 2005; 308(5728):1635-1638. [PubMed: 15831718]

4. [Accessed March 11, 2016] Human Microbiome Project - Home | NIH Common Fund. https:// commonfund.nih.gov/hmp/index

5. Gerber GK. The dynamic microbiome. FEBS Lett. 2014; 588(22):4131-4139. [PubMed: 24583074]

6. Zarrinpar A, Chaix A, Yooseph S, Panda S. Diet and feeding pattern affect the diurnal dynamics of the gut microbiome. Cell Metab. 2014; 20(6):1006-1017. [PubMed: 25470548]

7. Dong X-D, Li X-R, Luan J-J, et al. Bacterial communities in neonatal feces are similar to mothers' placentae. Can J Infect Dis Med Microbiol J Can Mal Infect Microbiol Médicale AMMI Can. 2015; 26(2):90-94.

8. Dominguez-Bello MG, Costello EK, Contreras M, et al. Delivery mode shapes the acquisition and structure of the initial microbiota across multiple body habitats in newborns. Proc Natl Acad Sci U S A. 2010; 107(26):11971-11975. [PubMed: 20566857] 
9. Biasucci G, Rubini M, Riboni S, Morelli L, Bessi E, Retetangos C. Mode of delivery affects the bacterial community in the newborn gut. Early Hum Dev. 2010; 86(Suppl 1):13-15.

10. Gregory KE, LaPlante RD, Shan G, Kumar DV, Gregas M. Mode of Birth Influences Preterm Infant Intestinal Colonization With Bacteroides Over the Early Neonatal Period. Adv Neonatal Care Off J Natl Assoc Neonatal Nurses. 2015; 15(6):386-393.

11. Wexler HM. Bacteroides: the good, the bad, and the nitty-gritty. Clin Microbiol Rev. 2007; 20(4): 593-621. [PubMed: 17934076]

12. Kasubuchi M, Hasegawa S, Hiramatsu T, Ichimura A, Kimura I. Dietary gut microbial metabolites, short-chain fatty acids, and host metabolic regulation. Nutrients. 2015; 7(4):2839-2849. [PubMed: 25875123]

13. Macfarlane GT, Macfarlane S. Bacteria, colonic fermentation, and gastrointestinal health. J AOAC Int. 2012; 95(1):50-60. [PubMed: 22468341]

14. Chen J, Li Y, Tian Y, et al. Interaction between Microbes and Host Intestinal Health: Modulation by Dietary Nutrients and Gut-Brain-Endocrine-Immune Axis. Curr Protein Pept Sci. 2015; 16(7): 592-603. [PubMed: 26122779]

15. Fan P, Li L, Rezaei A, Eslamfam S, Che D, Ma X. Metabolites of Dietary Protein and Peptides by Intestinal Microbes and their Impacts on Gut. Curr Protein Pept Sci. 2015; 16(7):646-654. [PubMed: 26122784]

16. Littman DR, Pamer EG. Role of the commensal microbiota in normal and pathogenic host immune responses. Cell Host Microbe. 2011; 10(4):311-323. [PubMed: 22018232]

17. Gaboriau-Routhiau V, Rakotobe S, Lécuyer E, et al. The key role of segmented filamentous bacteria in the coordinated maturation of gut helper T cell responses. Immunity. 2009; 31(4):677689. [PubMed: 19833089]

18. Mulder IE, Schmidt B, Lewis M, et al. Restricting microbial exposure in early life negates the immune benefits associated with gut colonization in environments of high microbial diversity. PloS One. 2011; 6(12):e28279. [PubMed: 22216092]

19. Mulder IE, Schmidt B, Stokes CR, et al. Environmentally-acquired bacteria influence microbial diversity and natural innate immune responses at gut surfaces. BMC Biol. 2009; 7:79. [PubMed: 19930542]

20. Munyaka PM, Khafipour E, Ghia J-E. External influence of early childhood establishment of gut microbiota and subsequent health implications. Front Pediatr. 2014; 2:109. [PubMed: 25346925]

21. Lozupone CA, Stombaugh JI, Gordon JI, Jansson JK, Knight R. Diversity, stability and resilience of the human gut microbiota. Nature. 2012; 489(7415):220-230. [PubMed: 22972295]

22. David LA, Materna AC, Friedman J, et al. Host lifestyle affects human microbiota on daily timescales. Genome Biol. 2014; 15(7):R89. [PubMed: 25146375]

23. Lax S, Smith DP, Hampton-Marcell J, et al. Longitudinal analysis of microbial interaction between humans and the indoor environment. Science. 2014; 345(6200):1048-1052. [PubMed: 25170151]

24. Joshi V, Matthews C, Aspiras M, de Jager M, Ward M, Kumar P. Smoking decreases structural and functional resilience in the subgingival ecosystem. J Clin Periodontol. 2014; 41(11):1037-1047. [PubMed: 25139209]

25. Allais L, Kerckhof F-M, Verschuere S, et al. Chronic cigarette smoke exposure induces microbial and inflammatory shifts and mucin changes in the murine gut. Environ Microbiol. 2015 Jun.

26. Campbell SC, Wisniewski PJ, Noji M, et al. The Effect of Diet and Exercise on Intestinal Integrity and Microbial Diversity in Mice. PloS One. 2016; 11(3):e0150502. [PubMed: 26954359]

27. Lax S, Hampton-Marcell JT, Gibbons SM, et al. Forensic analysis of the microbiome of phones and shoes. Microbiome. 2015; 3:21. [PubMed: 25969737]

28. Human Microbiome Project Consortium. Structure, function and diversity of the healthy human microbiome. Nature. 2012; 486(7402):207-214. [PubMed: 22699609]

29. Tilg H, Moschen AR, Kaser A. Obesity and the microbiota. Gastroenterology. 2009; 136(5):14761483. [PubMed: 19327360]

30. Caballero S, Pamer EG. Microbiota-mediated inflammation and antimicrobial defense in the intestine. Annu Rev Immunol. 2015; 33:227-256. [PubMed: 25581310] 
31. Prescott HC, Dickson RP, Rogers MAM, Langa KM, Iwashyna TJ. Hospitalization Type and Subsequent Severe Sepsis. Am J Respir Crit Care Med. 2015; 192(5):581-588. [PubMed: 26016947]

32. Defazio J, Fleming ID, Shakhsheer B, Zaborina O, Alverdy JC. The opposing forces of the intestinal microbiome and the emerging pathobiome. Surg Clin North Am. 2014; 94(6):11511161. [PubMed: 25440116]

33. Ubeda C, Pamer EG. Antibiotics, microbiota, and immune defense. Trends Immunol. 2012; 33(9): 459-466. [PubMed: 22677185]

34. Francino MP. Antibiotics and the Human Gut Microbiome: Dysbioses and Accumulation of Resistances. Front Microbiol. 2015; 6:1543. [PubMed: 26793178]

35. Buffie CG, Jarchum I, Equinda M, et al. Profound alterations of intestinal microbiota following a single dose of clindamycin results in sustained susceptibility to Clostridium difficile-induced colitis. Infect Immun. 2012; 80(1):62-73. [PubMed: 22006564]

36. Dethlefsen L, Relman DA. Incomplete recovery and individualized responses of the human distal gut microbiota to repeated antibiotic perturbation. Proc Natl Acad Sci U S A. 2011; 108(Suppl 1): 4554-4561. [PubMed: 20847294]

37. Jernberg C, Löfmark S, Edlund C, Jansson JK. Long-term ecological impacts of antibiotic administration on the human intestinal microbiota. ISME J. 2007; 1(1):56-66. [PubMed: 18043614]

38. Antonopoulos DA, Huse SM, Morrison HG, Schmidt TM, Sogin ML, Young VB. Reproducible community dynamics of the gastrointestinal microbiota following antibiotic perturbation. Infect Immun. 2009; 77(6):2367-2375. [PubMed: 19307217]

39. Chauv S, Fontaine GV, Hoang QP, et al. Risk of Resistant Organisms and Clostridium difficile with Prolonged Systemic Antibiotic Prophylaxis for Central Nervous System Devices. Neurocrit Care. 2016 Feb.

40. Stecher B, Chaffron S, Käppeli R, et al. Like will to like: abundances of closely related species can predict susceptibility to intestinal colonization by pathogenic and commensal bacteria. PLoS Pathog. 2010; 6(1):e1000711. [PubMed: 20062525]

41. Jakobsson HE, Jernberg C, Andersson AF, Sjölund-Karlsson M, Jansson JK, Engstrand L. Shortterm antibiotic treatment has differing long-term impacts on the human throat and gut microbiome. PloS One. 2010; 5(3):e9836. [PubMed: 20352091]

42. Yin J, Liao S-X, He Y, et al. Dysbiosis of Gut Microbiota With Reduced Trimethylamine-N-Oxide Level in Patients With Large-Artery Atherosclerotic Stroke or Transient Ischemic Attack. J Am Heart Assoc. 2015; 4(11)

43. Lapthorne S, Bines JE, Fouhy F, et al. Changes in the colon microbiota and intestinal cytokine gene expression following minimal intestinal surgery. World J Gastroenterol. 2015; 21(14):4150-4158. [PubMed: 25892864]

44. Earley ZM, Akhtar S, Green SJ, et al. Burn Injury Alters the Intestinal Microbiome and Increases Gut Permeability and Bacterial Translocation. PLoS ONE. 2015; 10(7)

45. Yu LC-H, Shih Y-A, Wu L-L, et al. Enteric dysbiosis promotes antibiotic-resistant bacterial infection: systemic dissemination of resistant and commensal bacteria through epithelial transcytosis. Am J Physiol Gastrointest Liver Physiol. 2014; 307(8):G824-G835. [PubMed: 25059827]

46. Ani C, Farshidpanah S, Bellinghausen Stewart A, Nguyen HB. Variations in organism-specific severe sepsis mortality in the United States: 1999-2008. Crit Care Med. 2015; 43(1):65-77. [PubMed: 25230374]

47. Almyroudis NG, Fuller A, Jakubowski A, et al. Pre- and post-engraftment bloodstream infection rates and associated mortality in allogeneic hematopoietic stem cell transplant recipients. Transpl Infect Dis Off J Transplant Soc. 2005; 7(1):11-17.

48. Taur Y, Xavier JB, Lipuma L, et al. Intestinal domination and the risk of bacteremia in patients undergoing allogeneic hematopoietic stem cell transplantation. Clin Infect Dis Off Publ Infect Dis Soc Am. 2012; 55(7):905-914.

49. Taur Y, Pamer EG. The intestinal microbiota and susceptibility to infection in immunocompromised patients. Curr Opin Infect Dis. 2013; 26(4):332-337. [PubMed: 23806896] 
50. Mai V, Torrazza RM, Ukhanova M, et al. Distortions in development of intestinal microbiota associated with late onset sepsis in preterm infants. PloS One. 2013; 8(1):e52876. [PubMed: 23341915]

51. Carl MA, Ndao IM, Springman AC, et al. Sepsis from the gut: the enteric habitat of bacteria that cause late-onset neonatal bloodstream infections. Clin Infect Dis Off Publ Infect Dis Soc Am. 2014; 58(9):1211-1218.

52. Greenwood C, Morrow AL, Lagomarcino AJ, et al. Early empiric antibiotic use in preterm infants is associated with lower bacterial diversity and higher relative abundance of Enterobacter. $\mathbf{J}$ Pediatr. 2014; 165(1):23-29. [PubMed: 24529620]

53. McMurtry VE, Gupta RW, Tran L, et al. Bacterial diversity and Clostridia abundance decrease with increasing severity of necrotizing enterocolitis. Microbiome. 2015; 3:11. [PubMed: 25810906]

54. Sheehan D, Moran C, Shanahan F. The microbiota in inflammatory bowel disease. J Gastroenterol. 2015; 50(5):495-507. [PubMed: 25808229]

55. Legaki E, Gazouli M. Influence of environmental factors in the development of inflammatory bowel diseases. World J Gastrointest Pharmacol Ther. 2016; 7(1):112-125. [PubMed: 26855817]

56. Cammarota G, Ianiro G, Cianci R, Bibbò S, Gasbarrini A, Currò D. The involvement of gut microbiota in inflammatory bowel disease pathogenesis: potential for therapy. Pharmacol Ther. 2015; 149:191-212. [PubMed: 25561343]

57. Tomasello G, Tralongo P, Damiani P, et al. Dismicrobism in inflammatory bowel disease and colorectal cancer: changes in response of colocytes. World J Gastroenterol. 2014; 20(48):1812118130. [PubMed: 25561781]

58. Candela M, Turroni S, Biagi E, et al. Inflammation and colorectal cancer, when microbiota-host mutualism breaks. World J Gastroenterol. 2014; 20(4):908-922. [PubMed: 24574765]

59. Gaidos JKJ, Bickston SJ. How to Optimize Colon Cancer Surveillance in Inflammatory Bowel Disease Patients. Inflamm Bowel Dis. 2016 Feb.

60. Perez-Chanona E, Trinchieri G. The role of microbiota in cancer therapy. Curr Opin Immunol. 2016; 39:75-81. [PubMed: 26820225]

61. Harrell L, Wang Y, Antonopoulos D, et al. Standard colonic lavage alters the natural state of mucosal-associated microbiota in the human colon. PloS One. 2012; 7(2):e32545. [PubMed: 22389708]

62. Olivas AD, Shogan BD, Valuckaite V, et al. Intestinal tissues induce an SNP mutation in Pseudomonas aeruginosa that enhances its virulence: possible role in anastomotic leak. PloS One. 2012; 7(8):e44326. [PubMed: 22952955]

63. Shogan BD, Belogortseva N, Luong PM, et al. Collagen degradation and MMP9 activation by Enterococcus faecalis contribute to intestinal anastomotic leak. Sci Transl Med. 2015; 7(286): 286 ra68.

64. Koleva PT, Bridgman SL, Kozyrskyj AL. The infant gut microbiome: evidence for obesity risk and dietary intervention. Nutrients. 2015; 7(4):2237-2260. [PubMed: 25835047]

65. Turnbaugh PJ, Ley RE, Mahowald MA, Magrini V, Mardis ER, Gordon JI. An obesity-associated gut microbiome with increased capacity for energy harvest. Nature. 2006; 444(7122):1027-1031. [PubMed: 17183312]

66. Liou AP, Paziuk M, Luevano J-M, Machineni S, Turnbaugh PJ, Kaplan LM. Conserved shifts in the gut microbiota due to gastric bypass reduce host weight and adiposity. Sci Transl Med. 2013; 5(178):178ra41.

67. Bateman BT, Schmidt U, Berman MF, Bittner EA. Temporal trends in the epidemiology of severe postoperative sepsis after elective surgery: a large, nationwide sample. Anesthesiology. 2010; 112(4):917-925. [PubMed: 20357565]

68. Vogel TR, Dombrovskiy VY, Lowry SF. Trends in postoperative sepsis: are we improving outcomes? Surg Infect. 2009; 10(1):71-78.

69. Clark JA, Coopersmith CM. Intestinal crosstalk: a new paradigm for understanding the gut as the "motor" of critical illness. Shock Augusta Ga. 2007; 28(4):384-393.

70. Zaborin A, Smith D, Garfield K, et al. Membership and behavior of ultra-low-diversity pathogen communities present in the gut of humans during prolonged critical illness. mBio. 2014; 5(5):e01361-e01314. [PubMed: 25249279] 
71. Petrosino JF, Highlander S, Luna RA, Gibbs RA, Versalovic J. Metagenomic pyrosequencing and microbial identification. Clin Chem. 2009; 55(5):856-866. [PubMed: 19264858]

72. Zoetendal EG, Rajilic-Stojanovic M, de Vos WM. High-throughput diversity and functionality analysis of the gastrointestinal tract microbiota. Gut. 2008; 57(11):1605-1615. [PubMed: 18941009]

73. Krezalek MA, DeFazio J, Zaborina O, Zaborin A, Alverdy JC. The Shift of an Intestinal "Microbiome" to A "Pathobiome" Governs the Course and Outcome of Sepsis Following Surgical Injury. Shock Augusta Ga. 2015 Nov.

74. Carrico CJ, Meakins JL, Marshall JC, Fry D, Maier RV. Multiple-organ-failure syndrome. Arch Surg Chic Ill 1960. 1986; 121(2):196-208.

75. Fink MP, Delude RL. Epithelial barrier dysfunction: a unifying theme to explain the pathogenesis of multiple organ dysfunction at the cellular level. Crit Care Clin. 2005; 21(2):177-196. [PubMed: 15781156]

76. Han X, Fink MP, Yang R, Delude RL. Increased iNOS activity is essential for intestinal epithelial tight junction dysfunction in endotoxemic mice. Shock Augusta Ga. 2004; 21(3):261-270.

77. Fink MP. Intestinal epithelial hyperpermeability: update on the pathogenesis of gut mucosal barrier dysfunction in critical illness. Curr Opin Crit Care. 2003; 9(2):143-151. [PubMed: 12657978]

78. Mittal R, Coopersmith CM. Redefining the gut as the motor of critical illness. Trends Mol Med. 2014; 20(4):214-223. [PubMed: 24055446]

79. Bloos F, Hinder F, Becker K, et al. A multicenter trial to compare blood culture with polymerase chain reaction in severe human sepsis. Intensive Care Med. 2010; 36(2):241-247. [PubMed: 19924398]

80. Moore FA, Moore EE, Poggetti R, et al. Gut bacterial translocation via the portal vein: a clinical perspective with major torso trauma. J Trauma. 1991; 31(5):629-636. discussion 636-638. [PubMed: 2030509]

81. Struelens MJ. Detection of microbial DNAemia: does it matter for sepsis management? Intensive Care Med. 2010; 36(2):193-195. [PubMed: 19924397]

82. Sertaridou E, Papaioannou V, Kolios G, Pneumatikos I. Gut failure in critical care: old school versus new school. Ann Gastroenterol Q Publ Hell Soc Gastroenterol. 2015; 28(3):309-322.

83. Puleo F, Arvanitakis M, Van Gossum A, Preiser J-C. Gut failure in the ICU. Semin Respir Crit Care Med. 2011; 32(5):626-638. [PubMed: 21989698]

84. MacFie J, Reddy BS, Gatt M, Jain PK, Sowdi R, Mitchell CJ. Bacterial translocation studied in 927 patients over 13 years. Br J Surg. 2006; 93(1):87-93. [PubMed: 16288452]

85. Adams CA, Xu DZ, Lu Q, Deitch EA. Factors larger than $100 \mathrm{kd}$ in post-hemorrhagic shock mesenteric lymph are toxic for endothelial cells. Surgery. 2001; 129(3):351-363. [PubMed: 11231464]

86. Lemaire LC, van Lanschot JB, Stoutenbeek CP, et al. Thoracic duct in patients with multiple organ failure: no major route of bacterial translocation. Ann Surg. 1999; 229(1):128-136. [PubMed: 9923810]

87. Senthil M, Brown M, Xu D-Z, Lu Q, Feketeova E, Deitch EA. Gut-lymph hypothesis of systemic inflammatory response syndrome/multiple-organ dysfunction syndrome: validating studies in a porcine model. J Trauma. 2006; 60(5):958-965. discussion 965-967. [PubMed: 16688055]

88. Magnotti LJ, Upperman JS, Xu DZ, Lu Q, Deitch EA. Gut-derived mesenteric lymph but not portal blood increases endothelial cell permeability and promotes lung injury after hemorrhagic shock. Ann Surg. 1998; 228(4):518-527. [PubMed: 9790341]

89. Badami CD, Senthil M, Caputo FJ, et al. Mesenteric lymph duct ligation improves survival in a lethal shock model. Shock Augusta Ga. 2008; 30(6):680-685.

90. Sambol JT, Lee MA, Caputo FJ, et al. Mesenteric lymph duct ligation prevents trauma/hemorrhage shock-induced cardiac contractile dysfunction. J Appl Physiol Bethesda Md 1985. 2009; 106(1): 57-65.

91. Deitch EA. Bacterial translocation or lymphatic drainage of toxic products from the gut: what is important in human beings? Surgery. 2002; 131(3):241-244. [PubMed: 11894026]

92. Deitch EA. Gut-origin sepsis: evolution of a concept. Surg J R Coll Surg Edinb Irel. 2012; 10(6): 350-356. 
93. Ferraro FJ, Rush BF, Simonian GT, et al. A comparison of survival at different degrees of hemorrhagic shock in germ-free and germ-bearing rats. Shock Augusta Ga. 1995; 4(2):117-120.

94. Souza DG, Vieira AT, Soares AC, et al. The essential role of the intestinal microbiota in facilitating acute inflammatory responses. J Immunol Baltim Md 1950. 2004; 173(6):4137-4146.

95. Alverdy JC, Chang EB. The re-emerging role of the intestinal microflora in critical illness and inflammation: why the gut hypothesis of sepsis syndrome will not go away. J Leukoc Biol. 2008; 83(3):461-466. [PubMed: 18160538]

96. Magalhaes JG, Tattoli I, Girardin SE. The intestinal epithelial barrier: how to distinguish between the microbial flora and pathogens. Semin Immunol. 2007; 19(2):106-115. [PubMed: 17324587]

97. Barbara G, Stanghellini V, Brandi G, et al. Interactions between commensal bacteria and gut sensorimotor function in health and disease. Am J Gastroenterol. 2005; 100(11):2560-2568. [PubMed: 16279914]

98. Rakoff-Nahoum S, Paglino J, Eslami-Varzaneh F, Edberg S, Medzhitov R. Recognition of commensal microflora by toll-like receptors is required for intestinal homeostasis. Cell. 2004; 118(2):229-241. [PubMed: 15260992]

99. Kelly D, Campbell JI, King TP, et al. Commensal anaerobic gut bacteria attenuate inflammation by regulating nuclear-cytoplasmic shuttling of PPAR-gamma and RelA. Nat Immunol. 2004; 5(1): 104-112. [PubMed: 14691478]

100. Arulampalam V, Greicius G, Pettersson S. The long and winding road to gut homeostasis. Curr Opin Gastroenterol. 2006; 22(4):349-353. [PubMed: 16760748]

101. Even-Tov E, Omer Bendori S, Valastyan J, et al. Social Evolution Selects for Redundancy in Bacterial Quorum Sensing. PLoS Biol. 2016; 14(2):e1002386. [PubMed: 26927849]

102. Fujiya M, Musch MW, Nakagawa Y, et al. The Bacillus subtilis quorum-sensing molecule CSF contributes to intestinal homeostasis via OCTN2, a host cell membrane transporter. Cell Host Microbe. 2007; 1(4):299-308. [PubMed: 18005709]

103. Donohoe DR, Garge N, Zhang X, et al. The microbiome and butyrate regulate energy metabolism and autophagy in the mammalian colon. Cell Metab. 2011; 13(5):517-526. [PubMed: 21531334]

104. Furusawa Y, Obata Y, Fukuda S, et al. Commensal microbe-derived butyrate induces the differentiation of colonic regulatory T cells. Nature. 2013; 504(7480):446-450. [PubMed: 24226770]

105. Arvans DL, Vavricka SR, Ren H, et al. Luminal bacterial flora determines physiological expression of intestinal epithelial cytoprotective heat shock proteins 25 and 72 . Am J Physiol Gastrointest Liver Physiol. 2005; 288(4):G696-G704. [PubMed: 15528251]

106. Shimizu K, Ogura H, Hamasaki T, et al. Altered gut flora are associated with septic complications and death in critically ill patients with systemic inflammatory response syndrome. Dig Dis Sci. 2011; 56(4):1171-1177. [PubMed: 20931284]

107. Shogan BD, Smith DP, Christley S, Gilbert JA, Zaborina O, Alverdy JC. Intestinal anastomotic injury alters spatially defined microbiome composition and function. Microbiome. 2014; 2:35. [PubMed: 25250176]

108. Hayakawa M, Asahara T, Henzan N, et al. Dramatic changes of the gut flora immediately after severe and sudden insults. Dig Dis Sci. 2011; 56(8):2361-2365. [PubMed: 21384123]

109. Albenberg L, Esipova TV, Judge CP, et al. Correlation between intraluminal oxygen gradient and radial partitioning of intestinal microbiota. Gastroenterology. 2014; 147(5):1055.e8-1063.e8. [PubMed: 25046162]

110. Winter SE, Winter MG, Xavier MN, et al. Host-derived nitrate boosts growth of E. coli in the inflamed gut. Science. 2013; 339(6120):708-711. [PubMed: 23393266]

111. Lupp C, Robertson ML, Wickham ME, et al. Host-mediated inflammation disrupts the intestinal microbiota and promotes the overgrowth of Enterobacteriaceae. Cell Host Microbe. 2007; 2(2): 119-129. [PubMed: 18005726]

112. Brown SP, Cornforth DM, Mideo N. Evolution of virulence in opportunistic pathogens: generalism, plasticity, and control. Trends Microbiol. 2012; 20(7):336-342. [PubMed: 22564248]

113. Fink D, Romanowski K, Valuckaite V, et al. Pseudomonas aeruginosa potentiates the lethal effect of intestinal ischemia-reperfusion injury: the role of in vivo virulence activation. J Trauma. 2011; 71(6):1575-1582. [PubMed: 22002612] 
114. Kohler JE, Zaborina O, Wu L, et al. Components of intestinal epithelial hypoxia activate the virulence circuitry of Pseudomonas. Am J Physiol Gastrointest Liver Physiol. 2005; 288(5):G1048-G1054. [PubMed: 15550562]

115. Patel NJ, Zaborina O, Wu L, et al. Recognition of intestinal epithelial HIF-1alpha activation by Pseudomonas aeruginosa. Am J Physiol Gastrointest Liver Physiol. 2007; 292(1):G134-G142. [PubMed: 16901993]

116. Zaborina O, Lepine F, Xiao G, et al. Dynorphin activates quorum sensing quinolone signaling in Pseudomonas aeruginosa. PLoS Pathog. 2007; 3(3):e35. [PubMed: 17367209]

117. Alverdy J, Holbrook C, Rocha F, et al. Gut-derived sepsis occurs when the right pathogen with the right virulence genes meets the right host: evidence for in vivo virulence expression in Pseudomonas aeruginosa. Ann Surg. 2000; 232(4):480-489. [PubMed: 10998646]

118. Babrowski T, Holbrook C, Moss J, et al. Pseudomonas aeruginosa virulence expression is directly activated by morphine and is capable of causing lethal gut-derived sepsis in mice during chronic morphine administration. Ann Surg. 2012; 255(2):386-393. [PubMed: 21989372]

119. Zaborin A, Romanowski K, Gerdes S, et al. Red death in Caenorhabditis elegans caused by Pseudomonas aeruginosa PAO1. Proc Natl Acad Sci U S A. 2009; 106(15):6327-6332. [PubMed: 19369215]

120. Behnsen J, Jellbauer S, Wong CP, et al. The cytokine IL-22 promotes pathogen colonization by suppressing related commensal bacteria. Immunity. 2014; 40(2):262-273. [PubMed: 24508234]

121. Rocha F, Laughlin R, Musch MW, Hendrickson BA, Chang EB, Alverdy J. Surgical stress shifts the intestinal Escherichia coli population to that of a more adherent phenotype: role in barrier regulation. Surgery. 2001; 130(1):65-73. [PubMed: 11436014]

122. Ayres JS, Trinidad NJ, Vance RE. Lethal inflammasome activation by a multidrug-resistant pathobiont upon antibiotic disruption of the microbiota. Nat Med. 2012; 18(5):799-806. [PubMed: 22522562]

123. Romanowski K, Zaborin A, Valuckaite V, et al. Candida albicans isolates from the gut of critically ill patients respond to phosphate limitation by expressing filaments and a lethal phenotype. PloS One. 2012; 7(1):e30119. [PubMed: 22253901]

124. Tullus K, Aronsson B, Marcus S, Möllby R. Intestinal colonization with Clostridium difficile in infants up to 18 months of age. Eur J Clin Microbiol Infect Dis Off Publ Eur Soc Clin Microbiol. 1989; 8(5):390-393.

125. Bien J, Palagani V, Bozko P. The intestinal microbiota dysbiosis and Clostridium difficile infection: is there a relationship with inflammatory bowel disease? Ther Adv Gastroenterol. 2013; 6(1):53-68.

126. Khailova L, Frank DN, Dominguez JA, Wischmeyer PE. Probiotic administration reduces mortality and improves intestinal epithelial homeostasis in experimental sepsis. Anesthesiology. 2013; 119(1):166-177. [PubMed: 23571641]

127. Petrof EO, Dhaliwal R, Manzanares W, Johnstone J, Cook D, Heyland DK. Probiotics in the critically ill: a systematic review of the randomized trial evidence. Crit Care Med. 2012; 40(12): 3290-3302. [PubMed: 22975886]

128. Morrow LE, Gogineni V, Malesker MA. Probiotics in the intensive care unit. Nutr Clin Pract Off Publ Am Soc Parenter Enter Nutr. 2012; 27(2):235-241.

129. Jacobi CA, Schulz C, Malfertheiner P. Treating critically ill patients with probiotics: Beneficial or dangerous? Gut Pathog. 2011; 3(1):2. [PubMed: 21352578]

130. Besselink MG, van Santvoort HC, Renooij W, et al. Intestinal barrier dysfunction in a randomized trial of a specific probiotic composition in acute pancreatitis. Ann Surg. 2009; 250(5):712-719. [PubMed: 19801929]

131. Morrow LE, Gogineni V, Malesker MA. Probiotic, prebiotic, and synbiotic use in critically ill patients. Curr Opin Crit Care. 2012; 18(2):186-191. [PubMed: 22343306]

132. Bowman KA, Broussard EK, Surawicz CM. Fecal microbiota transplantation: current clinical efficacy and future prospects. Clin Exp Gastroenterol. 2015; 8:285-291. [PubMed: 26566371]

133. Cammarota G, Ianiro G, Gasbarrini A. Fecal microbiota transplantation for the treatment of Clostridium difficile infection: a systematic review. J Clin Gastroenterol. 2014; 48(8):693-702. [PubMed: 24440934] 
134. Cammarota G, Masucci L, Ianiro G, et al. Randomised clinical trial: faecal microbiota transplantation by colonoscopy vs. vancomycin for the treatment of recurrent Clostridium difficile infection. Aliment Pharmacol Ther. 2015; 41(9):835-843. [PubMed: 25728808]

135. Youngster I, Sauk J, Pindar C, et al. Fecal microbiota transplant for relapsing Clostridium difficile infection using a frozen inoculum from unrelated donors: a randomized, open-label, controlled pilot study. Clin Infect Dis Off Publ Infect Dis Soc Am. 2014; 58(11):1515-1522.

136. Lee CH, Steiner T, Petrof EO, et al. Frozen vs Fresh Fecal Microbiota Transplantation and Clinical Resolution of Diarrhea in Patients With Recurrent Clostridium difficile Infection: A Randomized Clinical Trial. JAMA. 2016; 315(2):142-149. [PubMed: 26757463]

137. Zaborin A, Defazio JR, Kade M, et al. Phosphate-containing polyethylene glycol polymers prevent lethal sepsis by multidrug-resistant pathogens. Antimicrob Agents Chemother. 2014; 58(2):966-977. [PubMed: 24277029]

138. Zaborin A, Gerdes S, Holbrook C, Liu DC, Zaborina OY, Alverdy JC. Pseudomonas aeruginosa overrides the virulence inducing effect of opioids when it senses an abundance of phosphate. PloS One. 2012; 7(4):e34883. [PubMed: 22514685]

139. McArdle CS, McMillan DC, Hole DJ. Impact of anastomotic leakage on long-term survival of patients undergoing curative resection for colorectal cancer. Br J Surg. 2005; 92(9):1150-1154. [PubMed: 16035134]

140. Kang CY, Halabi WJ, Chaudhry OO, et al. Risk factors for anastomotic leakage after anterior resection for rectal cancer. JAMA Surg. 2013; 148(1):65-71. [PubMed: 22986932]

141. Krezalek MA, Umanskiy K, Hyman NH. Reoperative surgery following colorectal anastomotic leaks. Semin Colon Rectal Surg. 2015; 26(4):206-210.

142. Paun BC, Cassie S, MacLean AR, Dixon E, Buie WD. Postoperative complications following surgery for rectal cancer. Ann Surg. 2010; 251(5):807-818. [PubMed: 20395841]

143. Buchs NC, Gervaz P, Secic M, Bucher P, Mugnier-Konrad B, Morel P. Incidence, consequences, and risk factors for anastomotic dehiscence after colorectal surgery: a prospective monocentric study. Int J Colorectal Dis. 2008; 23(3):265-270. [PubMed: 18034250]

144. Matthiessen P, Hallböök O, Rutegård J, Simert G, Sjödahl R. Defunctioning stoma reduces symptomatic anastomotic leakage after low anterior resection of the rectum for cancer: a randomized multicenter trial. Ann Surg. 2007; 246(2):207-214. [PubMed: 17667498]

145. Shogan BD, Carlisle EM, Alverdy JC, Umanskiy K. Do we really know why colorectal anastomoses leak? J Gastrointest Surg Off J Soc Surg Aliment Tract. 2013; 17(9):1698-1707.

146. Wong NY, Eu KW. A defunctioning ileostomy does not prevent clinical anastomotic leak after a low anterior resection: a prospective, comparative study. Dis Colon Rectum. 2005; 48(11):20762079. [PubMed: 16086220]

147. Ogilvie JW, Dietz DW, Stocchi L. Anastomotic leak after restorative proctosigmoidectomy for cancer: what are the chances of a permanent ostomy? Int J Colorectal Dis. 2012; 27(10):12591266. [PubMed: 22350190]

148. den Dulk M, Smit M, Peeters KCMJ, et al. A multivariate analysis of limiting factors for stoma reversal in patients with rectal cancer entered into the total mesorectal excision (TME) trial: a retrospective study. Lancet Oncol. 2007; 8(4):297-303. [PubMed: 17395102]

149. Hallböök O, Sjödahl R. Anastomotic leakage and functional outcome after anterior resection of the rectum. Br J Surg. 1996; 83(1):60-62. [PubMed: 8653367]

150. Nesbakken A, Nygaard K, Lunde OC. Outcome and late functional results after anastomotic leakage following mesorectal excision for rectal cancer. Br J Surg. 2001; 88(3):400-404. [PubMed: 11260107]

151. Caulfield H, Hyman NH. Anastomotic leak after low anterior resection: a spectrum of clinical entities. JAMA Surg. 2013; 148(2):177-182. [PubMed: 23426596]

152. Bruce J, Krukowski ZH, Al-Khairy G, Russell EM, Park KG. Systematic review of the definition and measurement of anastomotic leak after gastrointestinal surgery. Br J Surg. 2001; 88(9):11571168. [PubMed: 11531861]

153. Karliczek A, Harlaar NJ, Zeebregts CJ, Wiggers T, Baas PC, van Dam GM. Surgeons lack predictive accuracy for anastomotic leakage in gastrointestinal surgery. Int J Colorectal Dis. 2009; 24(5):569-576. [PubMed: 19221768] 
154. Cohn I, Rives JD. Antibiotic protection of colon anastomoses. Ann Surg. 1955; 141(5):707-717. [PubMed: 14362409]

155. Cohen SR, Cornell CN, Collins MH, Sell JE, Blanc WA, Altman RP. Healing of ischemic colonic anastomoses in the rat: role of antibiotic preparation. Surgery. 1985; 97(4):443-446. [PubMed: 3983820]

156. Schardey HM, Joosten U, Finke U, et al. The prevention of anastomotic leakage after total gastrectomy with local decontamination. A prospective, randomized, double-blind, placebocontrolled multicenter trial. Ann Surg. 1997; 225(2):172-180. [PubMed: 9065294]

157. Kager L, Malmborg AS, Nord CE, Pieper R. The effect of short-term cefoxitin prophylaxis on the colonic microflora in patients undergoing colorectal surgery. Infection. 1982; 10(6):338-340. [PubMed: 6818152]

158. Kager L, Ljungdahl I, Malmborg AS, Nord CE, Pieper R, Dahlgren P. Antibiotic prophylaxis with cefoxitin in colorectal surgery: effect on the colon microflora and septic complications--a clinical model for prediction of the benefit and risks in using a new antibiotic in prophylaxis. Ann Surg. 1981; 193(3):277-282. [PubMed: 7011219]

159. Ohigashi S, Sudo K, Kobayashi D, Takahashi T, Nomoto K, Onodera H. Significant changes in the intestinal environment after surgery in patients with colorectal cancer. J Gastrointest Surg Off J Soc Surg Aliment Tract. 2013; 17(9):1657-1664.

160. Komen N, Slieker J, Willemsen P, et al. Polymerase chain reaction for Enterococcus faecalis in drain fluid: the first screening test for symptomatic colorectal anastomotic leakage. The Appealstudy: analysis of parameters predictive for evident anastomotic leakage. Int J Colorectal Dis. 2014; 29(1):15-21. [PubMed: 24122105]

161. Englesbe MJ, Brooks L, Kubus J, et al. A statewide assessment of surgical site infection following colectomy: the role of oral antibiotics. Ann Surg. 2010; 252(3):514-519. discussion 519-520. [PubMed: 20739852]

162. Deierhoi RJ, Dawes LG, Vick C, Itani KMF, Hawn MT. Choice of intravenous antibiotic prophylaxis for colorectal surgery does matter. J Am Coll Surg. 2013; 217(5):763-769. [PubMed: 24045142]

163. Matheson DM, Arabi Y, Baxter-Smith D, Alexander-Williams J, Keighley MR. Randomized multicentre trial of oral bowel preparation and antimicrobials for elective colorectal operations. Br J Surg. 1978; 65(9):597-600. [PubMed: 359083]

164. Siegel RL, Miller KD, Jemal A. Cancer statistics, 2015. CA Cancer J Clin. 2015; 65(1):5-29. [PubMed: 25559415]

165. Schwabe RF, Jobin C. The microbiome and cancer. Nat Rev Cancer. 2013; 13(11):800-812. [PubMed: 24132111]

166. Hooper LV, Littman DR, Macpherson AJ. Interactions Between the Microbiota and the Immune System. Science. 2012; 336(6086):1268-1273. [PubMed: 22674334]

167. Nestle FO, Di Meglio P, Qin J-Z, Nickoloff BJ. Skin immune sentinels in health and disease. Nat Rev Immunol. 2009; 9:679-691. [PubMed: 19763149]

168. Bevins CL, Salzman NH. Paneth cells, antimicrobial peptides and maintenance of intestinal homeostasis. Nat Rev Microbiol. 2011; 9(5):356-368. [PubMed: 21423246]

169. Pabst O. New concepts in the generation and functions of IgA. Nat Rev Immunol. 2012; 12(12): 821-832. [PubMed: 23103985]

170. Hooper LV, Littman DR, Macpherson AJ. Interactions Between the Microbiota and the Immune System. Science. 2012; 336(6086):1268-1273. [PubMed: 22674334]

171. Theriot CM, Young VB. Interactions Between the Gastrointestinal Microbiome and Clostridium difficile. Annu Rev Microbiol. 2015; 69(1):445-461. [PubMed: 26488281]

172. Kamada N, Kim Y-G, Sham HP, et al. Regulated Virulence Controls the Ability of a Pathogen to Compete with the Gut Microbiota. Science. 2012; 336(6086):1325-1329. [PubMed: 22582016]

173. Cornforth DM, Foster KR. Competition sensing: the social side of bacterial stress responses. Nat Rev Microbiol. 2013; 11(4):285-293. [PubMed: 23456045]

174. Karin M, Lawrence T, Nizet V. Innate Immunity Gone Awry: Linking Microbial Infections to Chronic Inflammation and Cancer. Cell. 2006; 124(4):823-835. [PubMed: 16497591]

175. Garrett WS. Cancer and the microbiota. Science. 2015; 348(6230):80-86. [PubMed: 25838377] 
176. Bultman SJ. Emerging roles of the microbiome in cancer. Carcinogenesis. 2014; 35(2):249-255. [PubMed: 24302613]

177. Turner JR. Intestinal mucosal barrier function in health and disease. Nat Rev Immunol. 2009; 9(11):799-809. [PubMed: 19855405]

178. Petnicki-Ocwieja T, Hrncir T, Liu Y-J, et al. Nod2 is required for the regulation of commensal microbiota in the intestine. Proc Natl Acad Sci. 2009; 106(37):15813-15818. [PubMed: 19805227]

179. Couturier-Maillard A, Secher T, Rehman A, et al. NOD2-mediated dysbiosis predisposes mice to transmissible colitis and colorectal cancer. J Clin Invest. 2013; 123(2):700-711. [PubMed: 23281400]

180. Rosenstiel P, Hellmig S, Hampe J, et al. Influence of polymorphisms in the NOD1/CARD4 and NOD2/CARD15 genes on the clinical outcome of Helicobacter pylori infection. Cell Microbiol. 2006; 8(7):1188-1198. [PubMed: 16819970]

181. Grivennikov SI, Wang K, Mucida D, et al. Adenoma-linked barrier defects and microbial products drive IL-23/IL-17-mediated tumour growth. Nature. 2012; 491(7423):254-258. [PubMed: 23034650]

182. Velcich A. Colorectal Cancer in Mice Genetically Deficient in the Mucin Muc2. Science. 2002; 295(5560):1726-1729. [PubMed: 11872843]

183. Mellman I, Coukos G, Dranoff G. Cancer immunotherapy comes of age. Nature. 2011; 480(7378):480-489. [PubMed: 22193102]

184. Eloe-Fadrosh EA, Rasko DA. The Human Microbiome: From Symbiosis to Pathogenesis. Annu Rev Med. 2013; 64(1):145-163. [PubMed: 23327521]

185. Huber S, Gagliani N, Zenewicz LA, et al. IL-22BP is regulated by the inflammasome and modulates tumorigenesis in the intestine. Nature. 2012; 491(7423):259-263. [PubMed: 23075849]

186. Elinav E, Strowig T, Henao-Mejia J, Flavell RA. Regulation of the Antimicrobial Response by NLR Proteins. Immunity. 2011; 34(5):665-679. [PubMed: 21616436]

187. Cuzick J, Otto F, Baron JA, et al. Aspirin and non-steroidal anti-inflammatory drugs for cancer prevention: an international consensus statement. Lancet Oncol. 2009; 10(5):501-507. [PubMed: 19410194]

188. Engle SJ, Ormsby I, Pawlowski S, et al. Elimination of colon cancer in germ-free transforming growth factor beta 1-deficient mice. Cancer Res. 2002; 62(22):6362-6366. [PubMed: 12438215]

189. Fukata M, Shang L, Santaolalla R, et al. Constitutive activation of epithelial TLR4 augments inflammatory responses to mucosal injury and drives colitis-associated tumorigenesis: Inflamm Bowel Dis. 2011; 17(7):1464-1473. [PubMed: 21674704]

190. Fukata M, Chen A, Vamadevan AS, et al. Toll-Like Receptor-4 Promotes the Development of Colitis-Associated Colorectal Tumors. Gastroenterology. 2007; 133(6):1869-1881. [PubMed: 18054559]

191. Karin M, Greten FR. NF- $\mathrm{BB}$ : linking inflammation and immunity to cancer development and progression. Nat Rev Immunol. 2005; 5(10):749-759. [PubMed: 16175180]

192. Mangerich A, Knutson CG, Parry NM, et al. Infection-induced colitis in mice causes dynamic and tissue-specific changes in stress response and DNA damage leading to colon cancer. Proc Natl Acad Sci. 2012; 109(27):E1820-E1829. [PubMed: 22689960]

193. Gur C, Ibrahim Y, Isaacson B, et al. Binding of the Fap2 Protein of Fusobacterium nucleatum to Human Inhibitory Receptor TIGIT Protects Tumors from Immune Cell Attack. Immunity. 2015; 42(2):344-355. [PubMed: 25680274]

194. Willett WC. Diet and Cancer: An Evolving Picture. JAMA. 2005; 293(2):233-234. [PubMed: 15644551]

195. Bouvard V, Loomis D, Guyton KZ, et al. Carcinogenicity of consumption of red and processed meat. Lancet Oncol. 2015; 16(16):1599-1600. [PubMed: 26514947]

196. Huycke MM, Gaskins HR. Commensal bacteria, redox stress, and colorectal cancer: mechanisms and models. Exp Biol Med Maywood NJ. 2004; 229(7):586-597. 
197. Reddy BS, Rivenson A. Inhibitory effect of Bifidobacterium longum on colon, mammary, and liver carcinogenesis induced by 2-amino-3-methylimidazo[4,5-f]quinoline, a food mutagen. Cancer Res. 1993; 53(17):3914-3918. [PubMed: 8358717]

198. Hullar, MAJ.; Burnett-Hartman, AN.; Lampe, JW. Gut Microbes, Diet, and Cancer. In: Zappia, V.; Panico, S.; Russo, GL.; Budillon, A.; Della Ragione, F., editors. Advances in Nutrition and Cancer. Vol. 159. Berlin, Heidelberg: Springer Berlin Heidelberg; 2014. p. 377-399.http:// link.springer.com/10.1007/978-3-642-38007-5_22 [Accessed December 22, 2015]

199. Carbonero F, Benefiel AC, Alizadeh-Ghamsari AH, Gaskins HR. Microbial pathways in colonic sulfur metabolism and links with health and disease. Front Physiol. 2012; 3(448)

200. Attene-Ramos MS, Wagner ED, Gaskins HR, Plewa MJ. Hydrogen sulfide induces direct radicalassociated DNA damage. Mol Cancer Res MCR. 2007; 5(5):455-459. [PubMed: 17475672]

201. Khandekar MJ, Cohen P, Spiegelman BM. Molecular mechanisms of cancer development in obesity. Nat Rev Cancer. 2011; 11(12):886-895. [PubMed: 22113164]

202. Bernstein C, Holubec H, Bhattacharyya AK, et al. Carcinogenicity of deoxycholate, a secondary bile acid. Arch Toxicol. 2011; 85(8):863-871. [PubMed: 21267546]

203. Yoshimoto S, Loo TM, Atarashi K, et al. Obesity-induced gut microbial metabolite promotes liver cancer through senescence secretome. Nature. 2013; 499(7456):97-101. [PubMed: 23803760]

204. Schulz MD, Atay Ç, Heringer J, et al. High-fat-diet-mediated dysbiosis promotes intestinal carcinogenesis independently of obesity. Nature. 2014; 514(7523):508-512. [PubMed: 25174708]

205. Singh N, Gurav A, Sivaprakasam S, et al. Activation of Gpr109a, Receptor for Niacin and the Commensal Metabolite Butyrate, Suppresses Colonic Inflammation and Carcinogenesis. Immunity. 2014; 40(1):128-139. [PubMed: 24412617]

206. Tang Y, Chen Y, Jiang H, Robbins GT, Nie D. G-protein-coupled receptor for short-chain fatty acids suppresses colon cancer. Int J Cancer. 2011; 128(4):847-856. [PubMed: 20979106]

207. Belcheva A, Irrazabal T, Robertson SJ, et al. Gut Microbial Metabolism Drives Transformation of Msh2-Deficient Colon Epithelial Cells. Cell. 2014; 158(2):288-299. [PubMed: 25036629]

208. Larrosa M, González-Sarrías A, García-Conesa MT, Tomás-Barberán FA, Espín JC. Urolithins, Ellagic Acid-Derived Metabolites Produced by Human Colonic Microflora, Exhibit Estrogenic and Antiestrogenic Activities. J Agric Food Chem. 2006; 54(5):1611-1620. [PubMed: 16506809]

209. Markle JGM, Frank DN, Mortin-Toth S, et al. Sex Differences in the Gut Microbiome Drive Hormone-Dependent Regulation of Autoimmunity. Science. 2013; 339(6123):1084-1088. [PubMed: 23328391]

210. Zackular JP, Baxter NT, Iverson KD, et al. The Gut Microbiome Modulates Colon Tumorigenesis. mBio. 2013; 4(6):e00692-e00613. [PubMed: 24194538]

211. Baxter NT, Zackular JP, Chen GY, Schloss PD. Structure of the gut microbiome following colonization with human feces determines colonic tumor burden. Microbiome. 2014; 2(1):1-11. [PubMed: 24468033]

212. Ahn J, Sinha R, Pei Z, et al. Human Gut Microbiome and Risk for Colorectal Cancer. JNCI J Natl Cancer Inst. 2013; 105(24):1907-1911. [PubMed: 24316595]

213. Marchesi, JR.; Dutilh, BE.; Hall, N., et al. Towards the Human Colorectal Cancer Microbiome. In: Ahmed, N., editor. PLoS ONE. Vol. 6. 2011. p. e20447

214. Nešić D, Hsu Y, Stebbins CE. Assembly and function of a bacterial genotoxin. Nature. 2004; 429(6990):429-433. [PubMed: 15164065]

215. Elwell CA, Dreyfus LA. DNase I homologous residues in CdtB are critical for cytolethal distending toxin-mediated cell cycle arrest. Mol Microbiol. 2000; 37(4):952-963. [PubMed: 10972814]

216. Toller IM, Neelsen KJ, Steger M, et al. Carcinogenic bacterial pathogen Helicobacter pylori triggers DNA double-strand breaks and a DNA damage response in its host cells. Proc Natl Acad Sci. 2011; 108(36):14944-14949. [PubMed: 21896770]

217. Lax AJ. Opinion: Bacterial toxins and cancer - a case to answer? Nat Rev Microbiol. 2005; 3(4): 343-349. [PubMed: 15806096] 
218. Putze J, Hennequin C, Nougayrede J-P, et al. Genetic Structure and Distribution of the Colibactin Genomic Island among Members of the Family Enterobacteriaceae. Infect Immun. 2009; 77(11): 4696-4703. [PubMed: 19720753]

219. Nougayrede J-P. Escherichia coli Induces DNA Double-Strand Breaks in Eukaryotic Cells. Science. 2006; 313(5788):848-851. [PubMed: 16902142]

220. Arthur JC, Perez-Chanona E, Muhlbauer M, et al. Intestinal Inflammation Targets CancerInducing Activity of the Microbiota. Science. 2012; 338(6103):120-123. [PubMed: 22903521]

221. Arthur JC, Gharaibeh RZ, Mühlbauer M, et al. Microbial genomic analysis reveals the essential role of inflammation in bacteria-induced colorectal cancer. Nat Commun. 2014; 5:4724. [PubMed: 25182170]

222. Buc, E.; Dubois, D.; Sauvanet, P., et al. High Prevalence of Mucosa-Associated E. coli Producing Cyclomodulin and Genotoxin in Colon Cancer. In: Battista, JR., editor. PLoS ONE. Vol. 8. 2013. p. e56964

223. Goodwin AC, Shields CED, Wu S, et al. Polyamine catabolism contributes to enterotoxigenic Bacteroides fragilis-induced colon tumorigenesis. Proc Natl Acad Sci. 2011; 108(37):1535415359. [PubMed: 21876161]

224. Sears CL. Enterotoxigenic Bacteroides fragilis: a Rogue among Symbiotes. Clin Microbiol Rev. 2009; 22(2):349-369. [PubMed: 19366918]

225. Wu S, Rhee K-J, Albesiano E, et al. A human colonic commensal promotes colon tumorigenesis via activation of T helper type $17 \mathrm{~T}$ cell responses. Nat Med. 2009; 15(9):1016-1022. [PubMed: 19701202]

226. Boleij A, Hechenbleikner EM, Goodwin AC, et al. The Bacteroides fragilis Toxin Gene Is Prevalent in the Colon Mucosa of Colorectal Cancer Patients. Clin Infect Dis. 2015; 60(2):208215. [PubMed: 25305284]

227. Sears CL, Pardoll DM. Perspective: Alpha-Bugs, Their Microbial Partners, and the Link to Colon Cancer. J Infect Dis. 2011; 203(3):306-311. [PubMed: 21208921]

228. McCoy, AN.; Araújo-Pérez, F.; Azcárate-Peril, A.; Yeh, JJ.; Sandler, RS.; Keku, TO. Fusobacterium Is Associated with Colorectal Adenomas. In: Goel, A., editor. PLoS ONE. Vol. 8. 2013. p. e53653

229. Kostic AD, Chun E, Robertson L, et al. Fusobacterium nucleatum Potentiates Intestinal Tumorigenesis and Modulates the Tumor-Immune Microenvironment. Cell Host Microbe. 2013; 14(2):207-215. [PubMed: 23954159]

230. Rubinstein MR, Wang X, Liu W, Hao Y, Cai G, Han YW. Fusobacterium nucleatum Promotes Colorectal Carcinogenesis by Modulating E-Cadherin/ $\beta$-Catenin Signaling via its FadA Adhesin. Cell Host Microbe. 2013; 14(2):195-206. [PubMed: 23954158]

231. Lu R, Liu X, Wu S, et al. Consistent activation of the -catenin pathway by Salmonella type-three secretion effector protein AvrA in chronically infected intestine. AJP Gastrointest Liver Physiol. 2012; 303(10):G1113-G1125.

232. Wistuba II, Gazdar AF. Gallbladder cancer: lessons from a rare tumour. Nat Rev Cancer. 2004; 4(9):695-706. [PubMed: 15343276]

233. Dutta U, Garg PK, Kumar R, Tandon RK. Typhoid carriers among patients with gallstones are at increased risk for carcinoma of the gallbladder. Am J Gastroenterol. 2000; 95(3):784-787. [PubMed: 10710075]

234. Lu R, Wu S, Zhang Y, et al. Enteric bacterial protein AvrA promotes colonic tumorigenesis and activates colonic beta-catenin signaling pathway. Oncogenesis. 2014; 3(6):e105. [PubMed: 24911876]

235. Arthur JC, Jobin C. The complex interplay between inflammation, the microbiota and colorectal cancer. Gut Microbes. 2013; 4(3):253-258. [PubMed: 23549517]

236. Uronis, JM.; Mühlbauer, M.; Herfarth, HH.; Rubinas, TC.; Jones, GS.; Jobin, C. Modulation of the Intestinal Microbiota Alters Colitis-Associated Colorectal Cancer Susceptibility. In: Bereswill, S., editor. PLoS ONE. Vol. 4. 2009. p. e6026

237. Ott SJ. Reduction in diversity of the colonic mucosa associated bacterial microflora in patients with active inflammatory bowel disease. Gut. 2004; 53(5):685-693. [PubMed: 15082587] 
238. Manichanh C. Reduced diversity of faecal microbiota in Crohn's disease revealed by a metagenomic approach. Gut. 2006; 55(2):205-211. [PubMed: 16188921]

239. Martin HM, Campbell BJ, Hart CA, et al. Enhanced Escherichia coli adherence and invasion in Crohn's disease and colon cancer. Gastroenterology. 2004; 127(1):80-93. [PubMed: 15236175]

240. Darfeuille-Michaud A, Neut C, Barnich N, et al. Presence of adherent Escherichia coli strains in ileal mucosa of patients with Crohn's disease. Gastroenterology. 1998; 115(6):1405-1413. [PubMed: 9834268]

241. Peek RM, Blaser MJ. Helicobacter pylori and gastrointestinal tract adenocarcinomas. Nat Rev Cancer. 2002; 2(1):28-37. [PubMed: 11902583]

242. Fox JG, Wang TC. Inflammation, atrophy, and gastric cancer. J Clin Invest. 2007; 117(1):60-69. [PubMed: 17200707]

243. Lofgren JL, Whary MT, Ge Z, et al. Lack of Commensal Flora in Helicobacter pylori-Infected INS-GAS Mice Reduces Gastritis and Delays Intraepithelial Neoplasia. Gastroenterology. 2011; 140(1):210.e4-220.e4. [PubMed: 20950613]

244. Brawner KM, Morrow CD, Smith PD. Gastric Microbiome and Gastric Cancer. Cancer J. 2014; 20(3):211-216. [PubMed: 24855010]

245. Islami F, Kamangar F. Helicobacter pylori and Esophageal Cancer Risk: A Meta-analysis. Cancer Prev Res (Phila Pa). 2008; 1(5):329-338.

246. zur Hausen H. Papillomaviruses and cancer: from basic studies to clinical application. Nat Rev Cancer. 2002; 2(5):342-350. [PubMed: 12044010]

247. Muñoz N, Castellsagué X, de González AB, Gissmann L. Chapter 1: HPV in the etiology of human cancer. Vaccine. 2006; 24:S1-S10. [PubMed: 16406226]

248. El-Serag HB. Epidemiology of Viral Hepatitis and Hepatocellular Carcinoma. Gastroenterology. 2012; 142(6):1264.e1-1273.e1. [PubMed: 22537432]

249. International Agency for Research on Cancer, Weltgesundheitsorganisation., editor. Lyon: IARC; 2012. IARC Monographs on the Evaluation of Carcinogenic Risks to Humans, Volume 100 B, Biological Agents: This Publication Represents the Views and Expert Opinions of an IARC Working Group on the Evaluation of Carcinogenic Risks to Humans, Which Met in Lyon, 24 February - 03 March 2009.

250. Velicer CM, Heckbert SR, Lampe JW, Potter JD, Robertson CA, Taplin SH. Antibiotic use in relation to the risk of breast cancer. JAMA. 2004; 291(7):827-835. [PubMed: 14970061]

251. Hunt, KM.; Foster, JA.; Forney, LJ., et al. Characterization of the Diversity and Temporal Stability of Bacterial Communities in Human Milk. In: Zilberstein, D., editor. PLoS ONE. Vol. 6. 2011. p. e21313

252. Xuan, C.; Shamonki, JM.; Chung, A., et al. Microbial Dysbiosis Is Associated with Human Breast Cancer. In: Takabe, K., editor. PLoS ONE. Vol. 9. 2014. p. e83744

253. Ochi A, Nguyen AH, Bedrosian AS, et al. MyD88 inhibition amplifies dendritic cell capacity to promote pancreatic carcinogenesis via Th2 cells. J Exp Med. 2012; 209(9):1671-1687. [PubMed: 22908323]

254. Farrell JJ, Zhang L, Zhou H, et al. Variations of oral microbiota are associated with pancreatic diseases including pancreatic cancer. Gut. 2012; 61(4):582-588. [PubMed: 21994333]

255. Ahn J, Chen CY, Hayes RB. Oral microbiome and oral and gastrointestinal cancer risk. Cancer Causes Control. 2012; 23(3):399-404. [PubMed: 22271008]

256. Wiest R, Garcia-Tsao G. Bacterial translocation (BT) in cirrhosis. Hepatology. 2005; 41(3):422433. [PubMed: 15723320]

257. Seki E, De Minicis S, Österreicher CH, et al. TLR4 enhances TGF- $\beta$ signaling and hepatic fibrosis. Nat Med. 2007; 13(11):1324-1332. [PubMed: 17952090]

258. Dapito DH, Mencin A, Gwak G-Y, et al. Promotion of Hepatocellular Carcinoma by the Intestinal Microbiota and TLR4. Cancer Cell. 2012; 21(4):504-516. [PubMed: 22516259]

259. Pragman, AA.; Kim, HB.; Reilly, CS.; Wendt, C.; Isaacson, RE. The Lung Microbiome in Moderate and Severe Chronic Obstructive Pulmonary Disease. In: Taube, C., editor. PLoS ONE. Vol. 7. 2012. p. e47305 
260. Sethi S, Murphy TF. Infection in the Pathogenesis and Course of Chronic Obstructive Pulmonary Disease. N Engl J Med. 2008; 359(22):2355-2365. [PubMed: 19038881]

261. Schreiber H, Nettesheim P, Lijinsky W, Richter CB, Walburg HE. Induction of lung cancer in germfree, specific-pathogen-free, and infected rats by $\mathrm{N}$-nitrosoheptamethyleneimine: enhancement by respiratory infection. J Natl Cancer Inst. 1972; 49(4):1107-1114. [PubMed: 5084122]

262. Melkamu T, Qian X, Upadhyaya P, O’Sullivan MG, Kassie F. Lipopolysaccharide Enhances Mouse Lung Tumorigenesis: A Model for Inflammation-Driven Lung Cancer. Vet Pathol. 2013; 50(5):895-902. [PubMed: 23381924]

263. Hoption Cann SA, van Netten JP, van Netten C. Dr William Coley and tumour regression: a place in history or in the future. Postgrad Med J. 2003; 79(938):672-680. [PubMed: 14707241]

264. Jessy T. Immunity over inability: The spontaneous regression of cancer. J Nat Sci Biol Med. 2011; 2(1):43-49. [PubMed: 22470233]

265. Wiemann B, Starnes CO. Coley's toxins, tumor necrosis factor and cancer research: a historical perspective. Pharmacol Ther. 1994; 64(3):529-564. [PubMed: 7724661]

266. De Bonis P, Albanese A, Lofrese G, et al. Postoperative Infection May Influence Survival in Patients With Glioblastoma: Simply a Myth? Neurosurgery. 2011; 69(4):864-869. [PubMed: 21900810]

267. Zbar B, Rapp HJ. Immunotherapy of guinea pig cancer with BCG. Cancer. 1974; 34(4):15321540.

268. BöHle A, Brandau S. Immune Mechanisms in Bacillus Calmette-Guerin Immunotherapy for Superficial Bladder Cancer. J Urol. 2003; 170(3):964-969. [PubMed: 12913751]

269. Pan ZK, Ikonomidis G, Lazenby A, Pardoll D, Paterson Y. A recombinant Listeria monocytogenes vaccine expressing a model tumour antigen protects mice against lethal tumour cell challenge and causes regression of established tumours. Nat Med. 1995; 1(5):471-477. [PubMed: 7585097]

270. Brockstedt DG, Giedlin MA, Leong ML, et al. Listeria-based cancer vaccines that segregate immunogenicity from toxicity. Proc Natl Acad Sci. 2004; 101(38):13832-13837. [PubMed: 15365184]

271. Zeller G, Tap J, Voigt AY, et al. Potential of fecal microbiota for early-stage detection of colorectal cancer. Mol Syst Biol. 2014; 10(11):766. [PubMed: 25432777]

272. Motta J-P, Bermudez-Humaran LG, Deraison C, et al. Food-Grade Bacteria Expressing Elafin Protect Against Inflammation and Restore Colon Homeostasis. Sci Transl Med. 2012; 4(158): 158 ra144.

273. Khazaie K, Zadeh M, Khan MW, et al. Abating colon cancer polyposis by Lactobacillus acidophilus deficient in lipoteichoic acid. Proc Natl Acad Sci. 2012; 109(26):10462-10467. [PubMed: 22689992]

274. Carroll IM, Andrus JM, Bruno-Barcena JM, Klaenhammer TR, Hassan HM, Threadgill DS. Antiinflammatory properties of Lactobacillus gasseri expressing manganese superoxide dismutase using the interleukin 10-deficient mouse model of colitis. AJP Gastrointest Liver Physiol. 2007; 293(4):G729-G738.

275. Davis CD, Milner JA. Gastrointestinal microflora, food components and colon cancer prevention. J Nutr Biochem. 2009; 20(10):743-752. [PubMed: 19716282]

276. Lim CC, Ferguson LR, Tannock GW. Dietary fibres as "prebiotics": Implications for colorectal cancer. Mol Nutr Food Res. 2005; 49(6):609-619. [PubMed: 15864790]

277. Borody TJ, Khoruts A. Fecal microbiota transplantation and emerging applications. Nat Rev Gastroenterol Hepatol. 2011; 9(2):88-96. [PubMed: 22183182]

278. Taur Y, Jenq RR, Perales M-A, et al. The effects of intestinal tract bacterial diversity on mortality following allogeneic hematopoietic stem cell transplantation. Blood. 2014; 124(7):1174-1182. [PubMed: 24939656]

279. Jenq RR, Ubeda C, Taur Y, et al. Regulation of intestinal inflammation by microbiota following allogeneic bone marrow transplantation. J Exp Med. 2012; 209(5):903-911. [PubMed: 22547653] 
280. Wallace BD, Wang H, Lane KT, et al. Alleviating Cancer Drug Toxicity by Inhibiting a Bacterial Enzyme. Science. 2010; 330(6005):831-835. [PubMed: 21051639]

281. Viaud S, Saccheri F, Mignot G, et al. The Intestinal Microbiota Modulates the Anticancer Immune Effects of Cyclophosphamide. Science. 2013; 342(6161):971-976. [PubMed: 24264990]

282. Iida N, Dzutsev A, Stewart CA, et al. Commensal Bacteria Control Cancer Response to Therapy by Modulating the Tumor Microenvironment. Science. 2013; 342(6161):967-970. [PubMed: 24264989]

283. Vetizou M, Pitt JM, Daillere R, et al. Anticancer immunotherapy by CTLA-4 blockade relies on the gut microbiota. Science. 2015; 350(6264):1079-1084. [PubMed: 26541610]

284. Sivan A, Corrales L, Hubert N, et al. Commensal Bifidobacterium promotes antitumor immunity and facilitates anti-PD-L1 efficacy. Science. 2015; 350(6264):1084-1089. [PubMed: 26541606]

285. Nair N, Kasai T, Seno M. Bacteria: prospective savior in battle against cancer. Anticancer Res. 2014; 34(11):6289-6296. [PubMed: 25368227]

286. Galán JE, Wolf-Watz H. Protein delivery into eukaryotic cells by type III secretion machines. Nature. 2006; 444(7119):567-573. [PubMed: 17136086]

287. Anderson JC, Clarke EJ, Arkin AP, Voigt CA. Environmentally Controlled Invasion of Cancer Cells by Engineered Bacteria. J Mol Biol. 2006; 355(4):619-627. [PubMed: 16330045]

288. Xiang S, Fruehauf J, Li CJ. Short hairpin RNA-expressing bacteria elicit RNA interference in mammals. Nat Biotechnol. 2006; 24(6):697-702. [PubMed: 16699500]

289. Lampe JW. The Human Microbiome Project: Getting to the Guts of the Matter in Cancer Epidemiology. Cancer Epidemiol Biomarkers Prev. 2008; 17(10):2523-2524. [PubMed: 18842991]

290. WHO | Obesity and overweight. [Accessed March 9, 2016] WHO. http://www.who.int/ mediacentre/factsheets/fs311/en/

291. Ogden CL, Carroll MD, Kit BK, Flegal KM. PRevalence of childhood and adult obesity in the united states, 2011-2012. JAMA. 2014; 311(8):806-814. [PubMed: 24570244]

292. Lavie CJ, Milani RV, Ventura HO. Obesity and cardiovascular disease: risk factor, paradox, and impact of weight loss. J Am Coll Cardiol. 2009; 53(21):1925-1932. [PubMed: 19460605]

293. De Pergola G, Silvestris F. Obesity as a Major Risk Factor for Cancer. J Obes. 2013; 2013

294. Swinburn BA, Sacks G, Hall KD, et al. The global obesity pandemic: shaped by global drivers and local environments. Lancet Lond Engl. 2011; 378(9793):804-814.

295. Church TS, Thomas DM, Tudor-Locke C, et al. Trends over 5 decades in U.S. occupation-related physical activity and their associations with obesity. PloS One. 2011; 6(5):e19657. [PubMed: 21647427]

296. Wardle J, Carnell S, Haworth CM, Plomin R. Evidence for a strong genetic influence on childhood adiposity despite the force of the obesogenic environment. Am J Clin Nutr. 2008; 87(2):398-404. [PubMed: 18258631]

297. Ley RE. Obesity and the human microbiome. Curr Opin Gastroenterol. 2010; 26(1):5-11. [PubMed: 19901833]

298. Ley RE, Bäckhed F, Turnbaugh P, Lozupone CA, Knight RD, Gordon JI. Obesity alters gut microbial ecology. Proc Natl Acad Sci U S A. 2005; 102(31):11070-11075. [PubMed: 16033867]

299. Waldram A, Holmes E, Wang Y, et al. Top-down systems biology modeling of host metabotypemicrobiome associations in obese rodents. J Proteome Res. 2009; 8(5):2361-2375. [PubMed: 19275195]

300. Ley RE, Turnbaugh PJ, Klein S, Gordon JI. Microbial ecology: human gut microbes associated with obesity. Nature. 2006; 444(7122):1022-1023. [PubMed: 17183309]

301. Turnbaugh PJ, Hamady M, Yatsunenko T, et al. A core gut microbiome in obese and lean twins. Nature. 2009; 457(7228):480-484. [PubMed: 19043404]

302. Kalliomäki M, Collado MC, Salminen S, Isolauri E. Early differences in fecal microbiota composition in children may predict overweight. Am J Clin Nutr. 2008; 87(3):534-538. [PubMed: 18326589] 
303. Goodson JM, Groppo D, Halem S, Carpino E. Is obesity an oral bacterial disease? J Dent Res. 2009; 88(6):519-523. [PubMed: 19587155]

304. Bäckhed F, Manchester JK, Semenkovich CF, Gordon JI. Mechanisms underlying the resistance to diet-induced obesity in germ-free mice. Proc Natl Acad Sci U S A. 2007; 104(3):979-984. [PubMed: 17210919]

305. Bäckhed F, Ding H, Wang T, et al. The gut microbiota as an environmental factor that regulates fat storage. Proc Natl Acad Sci U S A. 2004; 101(44):15718-15723. [PubMed: 15505215]

306. Turnbaugh PJ, Bäckhed F, Fulton L, Gordon JI. Diet-induced obesity is linked to marked but reversible alterations in the mouse distal gut microbiome. Cell Host Microbe. 2008; 3(4):213223. [PubMed: 18407065]

307. Turnbaugh PJ, Ridaura VK, Faith JJ, Rey FE, Knight R, Gordon JI. The effect of diet on the human gut microbiome: a metagenomic analysis in humanized gnotobiotic mice. Sci Transl Med. 2009; 1(6):6ra14.

308. Bäckhed F, Ley RE, Sonnenburg JL, Peterson DA, Gordon JI. Host-bacterial mutualism in the human intestine. Science. 2005; 307(5717):1915-1920. [PubMed: 15790844]

309. Louis P, Scott KP, Duncan SH, Flint HJ. Understanding the effects of diet on bacterial metabolism in the large intestine. J Appl Microbiol. 2007; 102(5):1197-1208. [PubMed: 17448155]

310. Topping DL, Clifton PM. Short-chain fatty acids and human colonic function: roles of resistant starch and nonstarch polysaccharides. Physiol Rev. 2001; 81(3):1031-1064. [PubMed: 11427691]

311. Scheppach W. Effects of short chain fatty acids on gut morphology and function. Gut. 1994; 35(1 Suppl):S35-S38. [PubMed: 8125387]

312. Schwiertz A, Taras D, Schäfer K, et al. Microbiota and SCFA in lean and overweight healthy subjects. Obes Silver Spring Md. 2010; 18(1):190-195.

313. Santacruz A, Marcos A, Wärnberg J, et al. Interplay between weight loss and gut microbiota composition in overweight adolescents. Obes Silver Spring Md. 2009; 17(10):1906-1915.

314. Samuel BS, Hansen EE, Manchester JK, et al. Genomic and metabolic adaptations of Methanobrevibacter smithii to the human gut. Proc Natl Acad Sci U S A. 2007; 104(25):1064310648. [PubMed: 17563350]

315. Mahowald MA, Rey FE, Seedorf H, et al. Characterizing a model human gut microbiota composed of members of its two dominant bacterial phyla. Proc Natl Acad Sci U S A. 2009; 106(14):5859-5864. [PubMed: 19321416]

316. David LA, Maurice CF, Carmody RN, et al. Diet rapidly and reproducibly alters the human gut microbiome. Nature. 2014; 505(7484):559-563. [PubMed: 24336217]

317. Duncan SH, Belenguer A, Holtrop G, Johnstone AM, Flint HJ, Lobley GE. Reduced dietary intake of carbohydrates by obese subjects results in decreased concentrations of butyrate and butyrate-producing bacteria in feces. Appl Environ Microbiol. 2007; 73(4):1073-1078. [PubMed: 17189447]

318. Hotamisligil GS, Erbay E. Nutrient sensing and inflammation in metabolic diseases. Nat Rev Immunol. 2008; 8(12):923-934. [PubMed: 19029988]

319. Lago R, Gómez R, Lago F, Gómez-Reino J, Gualillo O. Leptin beyond body weight regulation-current concepts concerning its role in immune function and inflammation. Cell Immunol. 2008; 252(1-2):139-145. [PubMed: 18289518]

320. Weisberg SP, McCann D, Desai M, Rosenbaum M, Leibel RL, Ferrante AW. Obesity is associated with macrophage accumulation in adipose tissue. J Clin Invest. 2003; 112(12):1796-1808. [PubMed: 14679176]

321. Hotamisligil GS, Peraldi P, Budavari A, Ellis R, White MF, Spiegelman BM. IRS-1-mediated inhibition of insulin receptor tyrosine kinase activity in TNF-alpha- and obesity-induced insulin resistance. Science. 1996; 271(5249):665-668. [PubMed: 8571133]

322. Spranger J, Kroke A, Möhlig M, et al. Inflammatory Cytokines and the Risk to Develop Type 2 Diabetes Results of the Prospective Population-Based European Prospective Investigation into Cancer and Nutrition (EPIC)-Potsdam Study. Diabetes. 2003; 52(3):812-817. [PubMed: 12606524] 
323. Schnabel RB, Yin X, Larson MG, et al. Multiple inflammatory biomarkers in relation to cardiovascular events and mortality in the community. Arterioscler Thromb Vasc Biol. 2013; 33(7):1728-1733. [PubMed: 23640499]

324. Chandra RK. Immune response in overnutrition. Cancer Res. 1981; 41(9 Pt 2):3795-3796. [PubMed: 7260949]

325. Cani PD, Amar J, Iglesias MA, et al. Metabolic endotoxemia initiates obesity and insulin resistance. Diabetes. 2007; 56(7):1761-1772. [PubMed: 17456850]

326. Pussinen PJ, Tuomisto K, Jousilahti P, Havulinna AS, Sundvall J, Salomaa V. Endotoxemia, immune response to periodontal pathogens, and systemic inflammation associate with incident cardiovascular disease events. Arterioscler Thromb Vasc Biol. 2007; 27(6):1433-1439. [PubMed: 17363692]

327. Creely SJ, McTernan PG, Kusminski CM, et al. Lipopolysaccharide activates an innate immune system response in human adipose tissue in obesity and type 2 diabetes. Am J Physiol Endocrinol Metab. 2007; 292(3):E740-E747. [PubMed: 17090751]

328. Pussinen PJ, Havulinna AS, Lehto M, Sundvall J, Salomaa V. Endotoxemia is associated with an increased risk of incident diabetes. Diabetes Care. 2011; 34(2):392-397. [PubMed: 21270197]

329. Tsukumo DML, Carvalho-Filho MA, Carvalheira JBC, et al. Loss-of-function mutation in Tolllike receptor 4 prevents diet-induced obesity and insulin resistance. Diabetes. 2007; 56(8):19861998. [PubMed: 17519423]

330. Ghoshal S, Witta J, Zhong J, de Villiers W, Eckhardt E. Chylomicrons promote intestinal absorption of lipopolysaccharides. J Lipid Res. 2009; 50(1):90-97. [PubMed: 18815435]

331. Reigstad CS, Lundén GO, Felin J, Bäckhed F. Regulation of serum amyloid A3 (SAA3) in mouse colonic epithelium and adipose tissue by the intestinal microbiota. PloS One. 2009; 4(6):e5842. [PubMed: 19513118]

332. Oliveira AG, Carvalho BM, Tobar N, et al. Physical exercise reduces circulating lipopolysaccharide and TLR4 activation and improves insulin signaling in tissues of DIO rats. Diabetes. 2011; 60(3):784-796. [PubMed: 21282367]

333. Carvalho BM, Guadagnini D, Tsukumo DML, et al. Modulation of gut microbiota by antibiotics improves insulin signalling in high-fat fed mice. Diabetologia. 2012; 55(10):2823-2834. [PubMed: 22828956]

334. Noria SF, Grantcharov T. Biological effects of bariatric surgery on obesity-related comorbidities. Can J Surg. 2013; 56(1):47-57. [PubMed: 23351555]

335. Sjöström L, Narbro K, Sjöström CD, et al. Effects of bariatric surgery on mortality in Swedish obese subjects. N Engl J Med. 2007; 357(8):741-752. [PubMed: 17715408]

336. Buchwald H, Avidor Y, Braunwald E, et al. Bariatric surgery: a systematic review and metaanalysis. JAMA. 2004; 292(14):1724-1737. [PubMed: 15479938]

337. Colquitt JL, Picot J, Loveman E, Clegg AJ. Surgery for obesity. Cochrane Database Syst Rev. 2009; (2):CD003641. [PubMed: 19370590]

338. Zhang H, DiBaise JK, Zuccolo A, et al. Human gut microbiota in obesity and after gastric bypass. Proc Natl Acad Sci U S A. 2009; 106(7):2365-2370. [PubMed: 19164560]

339. Furet J-P, Kong L-C, Tap J, et al. Differential adaptation of human gut microbiota to bariatric surgery-induced weight loss: links with metabolic and low-grade inflammation markers. Diabetes. 2010; 59(12):3049-3057. [PubMed: 20876719]

340. Sokol H, Pigneur B, Watterlot L, et al. Faecalibacterium prausnitzii is an anti-inflammatory commensal bacterium identified by gut microbiota analysis of Crohn disease patients. Proc Natl Acad Sci U S A. 2008; 105(43):16731-16736. [PubMed: 18936492]

341. Li JV, Ashrafian H, Bueter M, et al. Metabolic Surgery Profoundly Influences Gut Microbial-Host Metabolic Crosstalk. Gut. 2011; 60(9):1214-1223. [PubMed: 21572120]

342. Miras AD, le Roux CW. Mechanisms underlying weight loss after bariatric surgery. Nat Rev Gastroenterol Hepatol. 2013; 10(10):575-584. [PubMed: 23835488]

343. Woodard GA, Encarnacion B, Downey JR, et al. Probiotics improve outcomes after Roux-en-Y gastric bypass surgery: a prospective randomized trial. J Gastrointest Surg Off J Soc Surg Aliment Tract. 2009; 13(7):1198-1204. 
344. Nicholson JK, Holmes E, Wilson ID. Opinion: Gut microorganisms, mammalian metabolism and personalized health care. Nat Rev Microbiol. 2005; 3(5):431-438. [PubMed: 15821725]

345. Chan IS, Ginsburg GS. Personalized Medicine: Progress and Promise. Annu Rev Genomics Hum Genet. 2011; 12(1):217-244. [PubMed: 21721939]

346. Wilson ID. Drugs, bugs, and personalized medicine: Pharmacometabonomics enters the ring. Proc Natl Acad Sci. 2009; 106(34):14187-14188. [PubMed: 19706501]

347. Holmes E, Wilson ID, Nicholson JK. Metabolic Phenotyping in Health and Disease. Cell. 2008; 134(5):714-717. [PubMed: 18775301]

348. Patterson AD, Turnbaugh PJ. Microbial Determinants of Biochemical Individuality and Their Impact on Toxicology and Pharmacology. Cell Metab. 2014; 20(5):761-768. [PubMed: 25156450]

349. Clayton TA, Baker D, Lindon JC, Everett JR, Nicholson JK. Pharmacometabonomic identification of a significant host-microbiome metabolic interaction affecting human drug metabolism. Proc Natl Acad Sci. 2009; 106(34):14728-14733. [PubMed: 19667173]

350. Mathan VI, Wiederman J, Dobkin JF, Lindenbaum J. Geographic differences in digoxin inactivation, a metabolic activity of the human anaerobic gut flora. Gut. 1989; 30(7):971-977. [PubMed: 2759492]

351. Thorpe DW, Stringer AM, Gibson RJ. Chemotherapy-induced mucositis: the role of the gastrointestinal microbiome and toll-like receptors. Exp Biol Med. 2013; 238(1):1-6.

352. Wallace BD, Redinbo MR. The human microbiome is a source of therapeutic drug targets. Curr Opin Chem Biol. 2013; 17(3):379-384. [PubMed: 23680493]

353. Secher T, Normand S, Chamaillard M. NOD2 prevents emergence of disease-predisposing microbiota. Gut Microbes. 2013; 4(4):353-356. [PubMed: 23778641]

354. Jia W, Li H, Zhao L, Nicholson JK. Gut microbiota: a potential new territory for drug targeting. Nat Rev Drug Discov. 2008; 7(2):123-129. [PubMed: 18239669]

355. Bubnov RV, Spivak MY, Lazarenko LM, Bomba A, Boyko NV. Probiotics and immunity: provisional role for personalized diets and disease prevention. EPMA J. 2015; 6(1):14. [PubMed: 26221192]

356. Brandt LJ, Aroniadis OC, Mellow M, et al. Long-Term Follow-Up of Colonoscopic Fecal Microbiota Transplant for Recurrent Clostridium difficile Infection. Am J Gastroenterol. 2012; 107(7):1079-1087. [PubMed: 22450732]

357. Kelly CR, Kahn S, Kashyap P, et al. Update on Fecal Microbiota Transplantation 2015: Indications, Methodologies, Mechanisms, and Outlook. Gastroenterology. 2015; 149(1):223-237. [PubMed: 25982290]

358. Buffie CG, Pamer EG. Microbiota-mediated colonization resistance against intestinal pathogens. Nat Rev Immunol. 2013; 13(11):790-801. [PubMed: 24096337]

359. van Nood E, Vrieze A, Nieuwdorp M, et al. Duodenal infusion of donor feces for recurrent Clostridium difficile. N Engl J Med. 2013; 368(5):407-415. [PubMed: 23323867]

360. Shahinas D, Silverman M, Sittler T, et al. Toward an understanding of changes in diversity associated with fecal microbiome transplantation based on 16S rRNA gene deep sequencing. mBio. 2012; 3(5)

361. Taur Y, Pamer EG. Harnessing microbiota to kill a pathogen: Fixing the microbiota to treat Clostridium difficile infections. Nat Med. 2014; 20(3):246-247. [PubMed: 24603796]

362. Li M, Liang P, Li Z, et al. Fecal microbiota transplantation and bacterial consortium transplantation have comparable effects on the re-establishment of mucosal barrier function in mice with intestinal dysbiosis. Front Microbiol. 2015; 6:692. [PubMed: 26217323]

363. Buffie CG, Bucci V, Stein RR, et al. Precision microbiome reconstitution restores bile acid mediated resistance to Clostridium difficile. Nature. 2015; 517(7533):205-208. [PubMed: 25337874] 


\section{Biographies}

Monika A. Krezalek, MD is a general surgery resident at the University of Chicago and a research fellow in the laboratory of Dr. John C. Alverdy. She received her medical degree from Loyola Stritch School of Medicine. Her research interests include intestinal microbiome derangements in sepsis, gut-derived methicillin-resistant Staphylococcus aureus surgical site infections, intestinal microbiome effects on abdominal aortic aneurysm development, and surgical skills curriculum development for general surgery residents.

Kinga Skowron, MD is a general surgery resident at the University of Chicago. She received her medical degree from the University of Chicago Pritzker School of Medicine. She is a current research fellow in the laboratory of Dr. Ralph Weichselbaum, where she is studying the biology of stem-like cells within cancer, as well as the modeling of cancer in order to better understand and improve the application of immunotherapy.

Kristina Guyton, MD is a general surgery resident at the University of Chicago and a research fellow in the laboratory of Dr. John Alverdy. She received her medical degree from the Pritzker School of Medicine at the University of Chicago. Her research interests include surgical ethics, surgeon patient awake procedure communication, the collagen degradation capacity of enteric bacteria and the progression of anastomotic healing.

Baddr Shakhsheer, MD is a general surgery resident at the University of Chicago. He completed a research fellowship in the laboratory of Dr. John Alverdy and a fellowship in clinical medical ethics at the University of Chicago. He received his medical degree from Eastern Virginia Medical School. His research interests include gut microbiome interactions as it relates to anastomotic leak, clinical ethics, and the effect of opioids on intestinal anastomotic healing.

Sanjiv Hyoju, MD is a general surgeon from Nepal currently working as a research fellow in the laboratory of Dr. John Alverdy. He received his medical degree from Kathmandu University, Manipal College of Medical Sciences and further completed his surgical residency at B.P Koirala Institute of Health Sciences. His research focuses on understanding the role of gut microbiome on the outcomes of gut derived sepsis and anastomotic leak.

John C. Alverdy, MD FACS is the Sarah and Harold Lincoln Thompson Professor of Surgery and Executive Vice Chair of the University of Chicago Department of Surgery and is the current president of the Surgical Infection Society. He is the primary investigator for the past 15 years of a NIH funded basic science laboratory at the University of Chicago focused on host pathogen interactions in the gut and the role of the microbiome on inflammation, sepsis, postoperative complications and wound healing. 


\section{Table 1}

Bacterial conversion of dietary compounds and their role in tumor biology

\begin{tabular}{|l|l|l|l|l|}
\hline Dietary source & Example bacteria & Resulting molecules & Association with cancer & References \\
\hline Charred meats & $\begin{array}{l}\text { Anaerobic colonic } \\
\text { bacteria }\end{array}$ & $\begin{array}{l}\text { Heterocyclic amines, } \\
\text { N-nitroso compounds (NOC) }\end{array}$ & DNA damage & 197,198 \\
\hline Protein & Gut bacteria & Hydrogen sulfide & $\begin{array}{l}\text { Cell cycle dysregulation, } \\
\text { genotoxicity }\end{array}$ & 199,200 \\
\hline High fat diet & Clostridium species & $\begin{array}{l}\text { Increased secondary bile acids } \\
\text { (including deoxycholic acid or } \\
\text { DCA) }\end{array}$ & $\begin{array}{l}\text { Associated with hepatocellular, } \\
\text { colon and esophageal } \\
\text { carcinoma }\end{array}$ & 202,203 \\
\hline Fiber & Gut bacteria & $\begin{array}{l}\text { Short-chain fatty acids } \\
\text { (including butyrate) }\end{array}$ & $\begin{array}{l}\text { Conflicting evidence: possible } \\
\text { anti-inflammatory effect on } \\
\text { colonic mucosa vs. increased } \\
\text { risk of colon cancer }\end{array}$ & $205-207$ \\
\hline Soy & $\begin{array}{l}\text { Enterococcus faecium, } \\
\text { Lactobacillus mucosae }\end{array}$ & Flavonoids, phytoestrogens & $\begin{array}{l}\text { Flavonoids exert a protective } \\
\text { effect; phytoestrogens may } \\
\text { mimic endogenous estrogen and } \\
\text { increase risk of breast cancer }\end{array}$ & 198,208 \\
\hline
\end{tabular}


Table 2

Specific microbe-cancer relationships

\begin{tabular}{|l|l|l|l|}
\hline Organ & Microbe & Mechanism & References \\
\hline Colon & $\begin{array}{l}\text { Enterobacteriaceae species, } \\
\text { others }\end{array}$ & $\begin{array}{l}\text { Inflammation, epithelial damage and } \\
\text { translocation, direct bacterial toxicity }\end{array}$ & $236-240$ \\
\hline Stomach & H. pylori & $\begin{array}{l}\text { Hypochlorhydria, gastric atrophy, ulcers and } \\
\text { ultimately gastric cancer }\end{array}$ & $241-244$ \\
\hline Cervix, anus, oropharynx & Human papilloma virus & $\begin{array}{l}\text { E6 / E7 protein-mediated disruption of DNA } \\
\text { replication and apoptosis pathways }\end{array}$ & 246,247 \\
\hline Liver & Hepatitis viruses & Cirrhosis leading to hepatocellular carcinoma & 248,249 \\
\hline Gallbladder & S. typhi & AvrA protein causing dysregulated transcription & $231-234$ \\
\hline Lung & Multiple & $\begin{array}{l}\text { Hypothesized dysbiosis in COPD leading to } \\
\text { LPS-mediated cancer promotion }\end{array}$ & $259-262$ \\
\hline Pancreas & Multiple & $\begin{array}{l}\text { LPS increases cancer risk in setting of } \\
\text { pancreatitis }\end{array}$ & $253-255$ \\
\hline
\end{tabular}

